\title{
Pathological apoptosis in the developing brain
}

\author{
Klas Blomgren • Marcel Leist • Laurent Groc
}

Published online: 9 February 2007

(C) Springer Science + Business Media, LLC 2007

\begin{abstract}
More than half of the initially-formed neurons are deleted in certain brain regions during normal development. This process, whereby cells are discretely removed without interfering with the further development of remaining cells, is called programmed cell death (PCD). The term apoptosis is used to describe certain morphological manifestations of PCD. Many of the effectors of this developmental cell death program are highly expressed in the developing brain, making it more susceptible to accidental activation of the death machinery, e.g. following hypoxia-ischemia or irradiation. Recent evidence suggests, however, that activation and regulation of cell death mechanisms under pathological conditions do not exactly mirror physiological, developmentally regulated PCD. It may be argued that the conditions after e.g. ischemia are not even compatible with the execution of PCD as we know it. Under pathological conditions cells are exposed to various stressors, including energy failure, oxidative stress and unbalanced ion fluxes. This results in parallel triggering and potential overshooting of several different cell death pathways, which then interact with one
\end{abstract}

K. Blomgren $(\square)$

Center for Brain Repair and Rehabilitation, Institute of

Neuroscience and Physiology, Göteborg University,

SE 40530 Göteborg, Sweden

e-mail: klas.blomgren@neuro.gu.se

M. Leist

University of Konstanz,

Box M657, D-78457 Konstanz, Germany

e-mail:marcel.leist@uni-konstanz.de

L. Groc

CNRS-UMR 5091, Physiologie Cellulaire de la Synapse,

Université Bordeaux 2,

146 rue Léo Saignat,

33077 Bordeaux Cédex, France

e-mail: laurent.groc@u-bordeaux2.fr another and result in complex patterns of biochemical manifestations and cellular morphological features. These types of cell death are here called "pathological apoptosis," where classical hallmarks of PCD, like pyknosis, nuclear condensation and caspase-3 activation, are combined with non-PCD features of cell death. Here we review our current knowledge of the mechanisms involved, with special focus on the potential for therapeutic intervention tailored to the needs of the developing brain.

Keywords Brain development · Hypoxia-ischemia · Irradiation

\begin{tabular}{|c|c|}
\hline \multicolumn{2}{|c|}{ Abbreviations } \\
\hline AIF & apoptosis-inducing factor \\
\hline AMPA & $\begin{array}{l}\text { alpha-amino-3-hydroxy-5-methyl-4- } \\
\text { isoxazolepropionic acid }\end{array}$ \\
\hline APAF-1 & apoptosis protease-activating factor- 1 \\
\hline BDNF & brain-derived neurotrophic factor \\
\hline CREB & cAMP-response element-binding protein \\
\hline DG & dentate gyrus \\
\hline $\mathrm{EE}$ & early elimination \\
\hline ERK & extracellular signal-regulated protein kinase \\
\hline $\mathrm{HI}$ & hypoxia-ischemia \\
\hline IL & interleukin \\
\hline JNK & jun $N$-terminal kinase \\
\hline MAP kinase & mitogen-associated protein kinase \\
\hline $\mathrm{mtPT}$ & mitochondrial permeability transition \\
\hline NOS & nitrogen oxide synthase \\
\hline NGF & nerve growth factor \\
\hline NMDAR & $N$-methyl- $D$-aspartate receptor \\
\hline P7 & postnatal day 7 \\
\hline PCD & programmed cell death \\
\hline ROS & reactive oxygen species \\
\hline
\end{tabular}




$\begin{array}{ll}\text { SGZ } & \begin{array}{l}\text { subgranular zone (of the dentate gyrus) } \\ \text { SOD2 }\end{array} \\ \text { SVZ } & \begin{array}{l}\text { suberoxide dismutase } 2 \\ \text { subventricular zone (of the lateral } \\ \text { ventricular wall) }\end{array} \\ \text { TRX 2 } & \begin{array}{l}\text { thioredoxin 2 } \\ \text { XIAP }\end{array} \\ \text { X-linked inhibitor of apoptosis protein }\end{array}$

\section{Physiological cell death of developing neurons}

Strictly controlled cell death is an essential feature of normal development and homeostasis in multi-cellular organisms, in order to maintain the normal function of different organs and tissues, including the brain. A plethora of neurons is produced in the developing brain, many of which will be removed during embryonal and postnatal refinement of the central nervous system. This process of physiological cell death, whereby cells are discretely removed without interfering with the further development of remaining cells, is called programmed cell death (PCD). The term apoptosis is used to describe certain morphological manifestations of PCD [1]. The masterful work of A. Glücksmann has provided one of the best descriptions of physiological cell death during development regarding morphogenesis, phylogenesis, and histiogenesis [2]. In the nervous system, Hamburger and Levi-Montalcini described more specifically the developmental cell death of motoneurons and its regulation by factors located within the innervating region [3]. This pioneering work laid the ground for the concept that neuron precursors are produced in excess and later selected for survival or cell death depending on extracellular ("the neurotrophic hypothesis") [4] and intracellular processes [5]. In some brain regions more than half of the initially-formed neurons are lost during normal development but the extent and characteristics of PCD of developing neurons varies greatly at different stages of development and among different neuronal populations [6-8]. In many different species, two waves of neuronal cell death have been described during development [9]. The first wave consists of a large number of dividing neurons being eliminated during the peak of neurogenesis at mid-embryogenesis, here called early elimination (EE). The second wave consists of differentiated neurons dying while migrating toward their target locations or while connecting to target cells during the early postnatal period. The latter process is often referred as classical PCD [10]. These two waves likely serve two different purposes: to regulate the neuronal precursor pool size and to ensure the proper wiring of developing neuronal networks, respectively. In this first section of the review we intend to schematically describe the main pathways leading to physiological cell death, from the extracellular effectors to the intracellulars actors. Recent findings that shed new light on the PCD process are particularly emphasized and obvious differences between the developmental physiological PCD and pathological cell death are pointed out.

\section{Cell death during development: extracellular effectors}

From the establishment of the neurotrophic hypothesis, several key additional extracellular effectors have been shown to be instrumental in developmental PCD. Among these are neurotransmission in general, including the activation of $\mathrm{N}$ methyl- $D$-aspartate receptors (NMDAR), extracellular nucleotides, the glial sheet development, the guidance clues and the adhesive molecules (Fig. 1). It is then obvious that developmental PCD is a highly regulated process that depends on the input/output neuronal activity, controlled both by distant target cells and by local intercellular interactions (e.g. synapse formation).

\section{Positive regulators—death by neglect}

As described above, two waves of neuronal cell death have been described during development, EE and PCD. Schematically, it is proposed that both processes result in part from competition between neurons for a limited supply of neurotrophic factors, and PCD is considered to be the default pathway. Among the neurotrophic factors, the nerve growth factor (NGF) family (e.g. NGF itself, brain derived neurotrophic factor (BDNF) and neurotrophin 3), the glial cell-derived neurotrophic factor (GDNF), and the neurotrophic cytokines (e.g. ciliary neurotrophic factor (CNTF) and interleukin-6) have attracted the most attention $[11,12]$. Although both EE and PCD are modulated by neurotrophic factors, the source of the factors involved seem to differ significantly, such that the factors are produced locally during early cell death and distally during PCD [13]. Moreover, the same neuronal population can respond differently to the same neurotrophic factors depending on its maturational stage. For instance, GDNF has been shown to rescue dopaminergic neurons against $\mathrm{PCD}$ in vitro [14] and in vivo [15], but GDNF-/-mice that die perinatally exhibit normal numbers of nigral dopaminergic neuron precursors [16], indicating that early cell death (throughout EE) is insensitive to GDNF. Ret, a member of the receptor tyrosine kinase superfamily that transduces GDNF signaling, is required in vivo for the survival of dopamine neurons [17]. Along the same lines, chick retinal ganglion cells require NGF and BDNF to survive during early neural development whereas neither of these factors have any effect later during PCD [18]. The proneurotrophins that bind with high affinity to the p75 neurotrophin receptor (p75NTR) but lack the capacity to bind Trk receptors (e.g. NGF family receptor) can elicit apoptosis via p75NTR in neurons expressing survivalpromoting Trk receptors. However, this process seems to 
Fig. 1 Schematic representation of the extracellular effectors involved in the physiological survical/cell death balance of developing neurons. See text for details

\section{SURVIVAL DEATH}

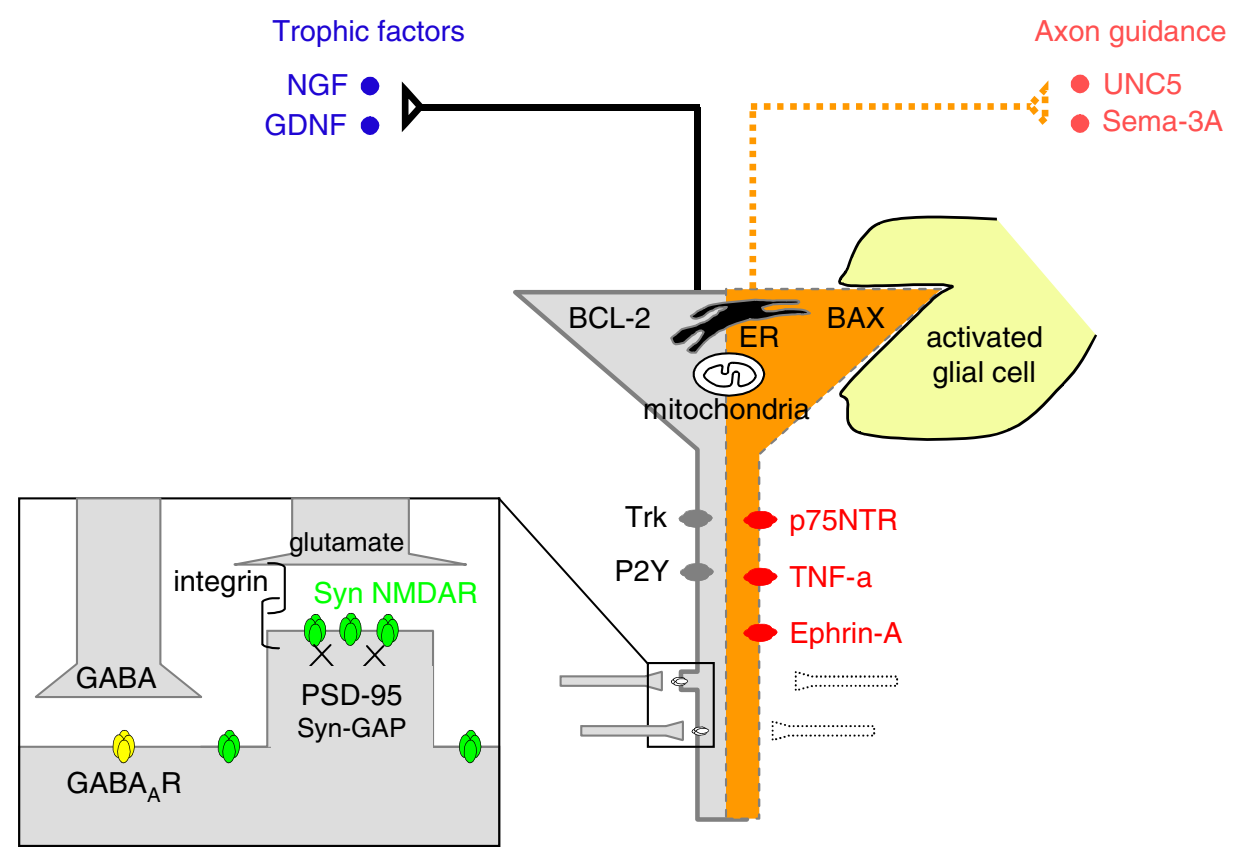

be mostly activated under pathological conditions [19]. In the retina, p75NTR and TrkA receptor regulate the number of retinal ganglion cell number in the EE phase but not at later stages, although their respective roles in triggering cell death remain unclear [20]. Moreover, during a defined developmental period trophic factors can have antagonistic effects on neurons. For instance, transforming growth factor (TGF)-beta and insulin display opposite effects in regulating postnatal apoptosis since TGF-beta induces apoptosis whereas insulin has a well-described anti-apoptotic effect [21]. In all, the regulation of neuronal death during development by neurotrophic factors relies on a finely tuned balance between numerous partners, which can be disrupted under pathological conditions.

Recently, it has been shown that neurotransmission plays a key role in controlling developmental cell death (Fig. 1). An obvious difference between EE and PCD is the influence of neurotransmission and synaptic activity [22]. Suppression of synaptic activity during embryonic development does not have any obvious effects on brain, neuronal or synaptic morphology [23]. In contrast, during the postnatal period, when synaptogenesis is at its peak, massive neuronal cell death can be triggered by an acute blockade of glutamate receptors [24-29]. Demonstrating the pivotal role of the glutamatergic NMDA receptor in controlling developmental cell death has been a major recent advance in our understanding of death induction in developing neurons. Blockade of NMDA receptors induces cell death during the early postnatal period in rodents and monkeys [24, 26, 30-32]. The localization of the NMDA receptors, i.e. in the synaptic or extrasynap- tic membranes, influences the survival balance of neurons. Indeed, calcium influx through synaptic or extra-synaptic NMDA receptors produced opposite effects on CREB function, BDNF gene regulation, neuron survival [33] and Akt phosphorylation [34]. There are even situations where increased intracellular concentrations of calcium can foster neuronal survival [35] and calcium depletion may induce cell death [36]. Peripheral sympathetic and sensory neurons are strictly dependent on NGF for survival directly after isolation and have intracellular calcium levels of about $100 \mathrm{nM}$, rising to $250 \mathrm{nM}$ after 3 weeks in culture, concomitantly losing their requirement for NGF to prevent apoptosis. Artificially raising the intracellular calcium levels early during culture abolishes the NGF requirement, indicating that at least some neuronal populations have a developmentally regulated set-point, and that intracellular calcium concentrations determine their dependence on trophic factors and control neuronal survival [37, 38].

The activation of synaptic NMDARs that are present at the surface of neurons at early stages [39] has a trophic effect on neuronal survival. An elegant recent study has even shown that the survival of new neurons is competitively regulated by their own NMDA receptors during a short, critical period soon after birth [40]. Such a role for glutamate during physiological cell death stands in contrast to its potent cell death-inducing effect under pathological conditions, where massive release of glutamate induces spill-over from the synapse, activation of extrasynaptic NMDA receptors and cell death [41] and the NMDAR antagonist MK-801 is highly protective in models of ischemia in the developing 
brain [42-44]. Furthermore, the AMPA type (alpha-amino3-hydroxy-5-methyl-4-isoxazolepropionic acid) glutamatergic receptor, does not appear to play a role in developmental cell death, whereas changes in AMPA signaling have been reported in pathological models of glutamate/NMDAmediated cell death [24-26, 44, 45]. Hence, during neuronal network formation most neurotransmission has trophic effects and, conversely, insufficient activity is likely proapoptotic. Further investigations are clearly needed to clarify, for instance, the role of different neurotransmitters in this process [46], the role of synaptic components [28, 47] and whether neurotransmitter-induced neuronal survival simply requires depolarization [48], which can be achieved by both glutamate and GABA at early stages, or whether it is ligand specific. Other extracellular molecules acting on gated channels, such as nucleotides (e.g. ATP), also modulate neuronal survival during development $[49,50]$, further suggesting that the neuronal activity status is a key control point for neuronal survival.

Negative regulators-death by murder

In contrast to the cell death mechanism induced by lack of survival signaling, some extracellular molecules have been shown to act as direct inducers of neuronal death during development. For instance, the proneurotrophins that bind with high affinity to the p75 neurotrophin receptor (p75NTR) can directly induce neuronal death. These receptors are often referred as "death receptors" and are coupled to specific apoptotic effectors (e.g. caspase-8). Fas, a member of the TNF-alpha receptor family, is expressed during development in the spinal cord, hippocampus, and cortex [51] and is involved in the death of motoneurons [52]. However, convincing evidence from in vivo studies is still lacking [53, 54].

Interestingly, over the last years, several molecules involved in various steps of neuronal development were unexpectedly found to regulate physiological neuronal death. Glial cells have emerged as key regulators of neuronal development, regulating for instance the number of neurons at early stages by dynamically influencing neural precursors divisions, and at later stages by promoting neuronal cell death by engulfment [55]. Moreover, the chemorepellent netrin-1 receptors, UNC5 proteins and the axonal guidance molecule semaphorin 3A mediate neuronal cell death [56, 57]. Although it still needs to be firmly established, it is possible that glial cells and the guidance molecules actively remove neurons that are mislocated, where cell density is too high, or neurons that send their axons to inappropriate target areas. Consistently, molecules from the extracellular matrix component family, integrin and ephrin, that ensure proper cell adhesion and cell recognition, play a role in developmental apoptosis $[58,59]$.

\section{Cell death during development: intracellular effectors}

Over the last decade, the number of molecules involved in cell death has increased dramatically. In this section, we mainly focus on the intracellular molecules that are activated during cell death of developing neurons, with special emphasis on the difference between EE and PCD and between physiological and pathological cell death. The molecular cascades will be discussed in the next sections. The morphological characteristics of dying immature neurons during development have revealed heterogeneity in the cell death process. Schematically, three types of cell death have been described [60]. The first is characterized by shrinkage of the nucleus with condensed chromatin (internucleosomal DNA cleavage), cytoplasmic condensation and fragmentation of the neurons in "cellular bodies". This cell death type, called apoptosis [1], is by far the most abundant during PCD [60]. The second type is characterized by the appearance of autophagic vesicles within the cytoplasm. The third type exhibits swelling of cellular organelles, resembling a necrotic morphology. The significance of this morphological heterogeneity is still unclear and apoptosis remains by far the most studied of these processes. Schematically the pathways that lead to apoptosis can be subdivided into external and internal signals, as described above. Studies from knockout mice have provided essential information on the effectors $[6,61$, 62]. Activation of the caspase-9/APAF-1 complex, which in turn activates caspase- 3 , is a central pathway for PCD, and to some extent EE. The suppression of these effectors by genetic targeting produced severe brain malformations during brain development (including hyperplasia), indicating insufficient removal of neuronal precursors and postmitotic neurons [6, 63-68]. However, none of these mutations produced alterations in the spinal cord or brainstem structures [66], or in other organs where extensive PCD occurs, such as the thymus [63], indicating that involvement of specific caspases may be brain region, neuronal type, and maturational stage dependent. Consistently, apoptosis of proliferating cerebellar granule cells and young pre-migratory cells occurs in the absence of caspase- 3 cleavage, whereas cell death of post-mitotic migratory neurons is directly linked to caspase-3 activation [69]. Other caspases, such as caspase-2, which is an early checkpoint for apoptosis initiation in cortical neurons [70], have been involved and further investigations will shed light on additional apoptotic effectors during developmental cell death of neurons. Upstream of caspase activation, the Bcl-2 family constitutes a critical intracellular checkpoint in the intrinsic pathways of neuronal apoptosis during development [62]. Genetic mutations of the Bcl-2 family members do not produce hyperplasia or the massive brain malformations that were observed in, for instance, caspase-3-deficient mice, but neuronal cell death of postnatal motoneurons, sensory, retinal, cortical and cerebellar 
neurons is affected [6,71-78]. The commitment for developing neurons toward survival or cell death would then depend on the ratio between anti-apoptotic (e.g. Bcl-2 and Bcl- $\mathrm{X}_{\mathrm{L}}$ ) and pro-apoptotic (e.g. Bax) factors [62]. Upon receipt of a neuronal death signal Bax/Bak is a gateway to the intrinsic pathway operative at the mitochondrial level, which is a critical organelle for developmental apoptosis. In addition to mitochondria, proteins from the endoplasmic reticulum and the endosomal system also activate the apoptotic machinery during developmental cell death of neurons [79-81]. Furthermore, the PI3K-Akt signaling pathway plays a critical role in mediating survival signals in a wide range of neuronal cell types. The identification of a number of substrates for the serine/threonine kinase Akt suggests that it blocks cell death by both impinging on the cytoplasmic cell death machinery and by regulating the expression of genes involved in cell death and survival [82]. It should also be mentioned that additional molecules such as the kinesin superfamily protein 4 (KIF4) and poly (ADP-ribose) polymerase-1 (PARP-1) [83], the notch signaling pathway [84, 85], the p53 family member p63 [86], survivin, an inhibitor of apoptosis protein (IAP) [87], have been involved in EE and PCD. A distinct difference in the apoptotic mediators between EE and PCD is that EE involves a reentry into the cell cycle [88, 89]. For instance, the neurotrophin-3 withdrawal-induced developmental cell death of dorsal root ganglia neuron precursors was regulated by cell cycle molecules such as the cyclins D3 and E [90]. However, during PCD of postmitotic motoneurons [91], cerebellar [92, 93] and nigral dopamine neurons, cell cycle pathways are not activated, suggesting a specific role for cell cycle regulation in $\mathrm{EE}$ of neuronal precursors.

Excessive oxidative stress in neurons, mainly mediated by reactive oxygen species (ROS) [94], has been highlighted as a candidate pathway to trigger PCD [95-101]. For instance, the apoptotic death of cultured sympathetic neurons or motoneurons can be blocked by ROS scavengers or overexpression of antioxidant enzymes [96, 102]. A particularly interesting model to study the role of oxidative stress during PCD is the dopaminergic system. Nigral dopamine neurons are highly sensitive to oxidative stress under pathological conditions, such as models of Parkinsons disease [98, 103]. Antioxidants protect cultured dopamine neurons from death due to serum deprivation [104-108], suggesting that developing dopamine neurons undergo oxidative stress and subsequently PCD. However, in vitro models are not always readily translated into physiological PCD since important differences between cultured and in vivo dopaminergic neurons have been observed. For instance, cultured nigral dopamine neurons do not express functional NMDA receptors [109] whereas nigral dopamine neurons from postnatal brains do display functional NMDA signaling [110]. It is unclear to what extent the in vitro mechanisms of oxidative stress can be applied to physiological conditions. Moreover, studies on the physiological cell death of postnatal nigral dopaminergic neurons $[111,112]$ clearly showed that the in vivo PCD is not dependent on oxidative stress [113-116]. Nitric oxide (NO) was found not to be involved in the PCD of dopamine neurons [108, 115], although there may exist differences between brain areas [117]. How can initial reports of high neuronal ROS contents during cell death be reconciled with a negative role for oxidative stress in PCD? A recent finding indicated that ROS accumulation in neurons accompanies the differentiation of progenitors into neurons, indicating that ROS play a role in the development of the neuronal phenotype and that high ROS contents for a neuron may not necessarily be a sign of cell death [118]. Based on these studies, it seems unlikely that the highly reactive and non-specific ROS involved in pathological cell death would control the highly coordinated PCD under physiological conditions $[119,120]$.

In conclusion, depending on the trigger (see Fig. 1) several cell death cascades can lead developing neurons to apoptosis. The EE and PCD of neurons seem to have distinct main molecular pathways but common effectors are observed (e.g. caspases). Comparing the molecular pathways of physiological and pathological cell death of developing neurons, e.g. the oxidative stress, it appears that pathological cell death does not replicate the physiological one, although effectors may be shared.

\section{Pathological apoptosis}

Why "pathological" apoptosis?

There are reasons to consider PCD occurring after a pathological insult, such as hypoxia-ischemia (HI) or irradiation (IR), as different from the normal physiological, developmentally regulated PCD. The reasons for this will be discussed in this second part of the review. An ischemic insult will affect fully differentiated neurons more than immature precursors, whereas IR will affect predominantly precursor cells. Mature, post-mitotic neurons require much energy to maintain ionic gradients and cellular processes up to 40,000 times longer than their cell bodies and are therefore more susceptible to HI and subsequent energy depletion [121]. Neuronal precursors in the neurogenic regions of the postnatal brain, mainly the dentate gyrus subgranular zone (SGZ) in the hippocampus and the subventricular zone (SVZ) of the lateral ventricular wall, proliferate and are therefore more susceptible to the DNA damage caused by IR [122]. Morphological characteristics of both apoptosis and necrosis may be present after $\mathrm{HI}$ in the immature brain, even in the same cell [123, 124], and the relative appearance of these features is age-dependent [125]. 
Under pathological conditions several cell death pathways are activated simultaneously

A: The classical apoptosis pathway based on the specific release of protein factors from the mitochondrial intermembrane space. These factors include cytochrome $c$ and AIF and their respective effectors can interact with one another and trigger either apoptosis (when caspases predominate) or apoptosis-like death (when AIF predominates) (Fig. 2).

B: Excessive elevation of intracellular calcium, which can lead to the activation of hydrolytic enzymes and trigger mitochondrial permeablity transition (Fig. 3).

$\mathrm{C}$ : Ionic imbalances and intracellular edema due to excessive $\mathrm{Na}$ and $\mathrm{Cl}$ influx.

D: Oxidative stress resulting in depletion of glutathione and increased levels of unbuffered ROS (Fig. 3).

Interactions between pathways

Multiple interactions between these pathways take place. For example, caspase activation (pathway A) can be modulated by all the other three pathways in different ways. ATP is required for apoptosome formation and subsequent caspase activation, but within a couple of minutes after the onset of HI the tissue will suffer from complete loss of ATP, interfering with caspase activation. Very soon after the drop in ATP, ionic gradients can no longer be maintained and intracellular $\mathrm{Ca}, \mathrm{Na}$ and $\mathrm{Cl}$ concentrations increase, triggering mitochondrial dysfunction and activation of many enzymes, including phospholipases and calpains. Formation of the apoptosome is also sensitive to the ionic composition of the cytosol and excessive influx of sodium would also block the process. Finally, cysteine proteases, including caspases are sensitive to the redox balance of the cell and can be inactivated under oxidative conditions. These are just a few examples out of many possible pathway interactions. Sometimes one of the pathways can be partially activated before another one takes over, explaining the mixed morphologies with features of both apoptosis and necrosis found under such conditions. For example, a cell may activate the apoptotic program and half way down the road experience a severe lack of ATP, resulting in disruption of membrane potential, influx of ions with subsequent swelling and protease activation, resulting in morphological signs of necrosis being added to the apoptotic morphology already partially established. The reverse may also occur. Neurons in the penumbral border zone of an infarct area will initially experience complete ATP depletion, activating mechanisms of necrosis and, upon restoration of blood flow, energy levels will be restored, interrupting the necrotic pathways and enabling activation of apoptotic mechanisms.
Delayed, "secondary" energy failure

The onset of HI results in depletion of oxygen in the ischemic tissue within seconds, resulting in impaired mitochondrial oxidative phosphorylation. ATP levels are preserved for a couple of minutes through anaerobic glycolysis and through reaction of ADP with phosphocreatine catalyzed by creatine kinase [126]. Restoration of blood flow within 20-30 min in rodent models results in substantial recovery of metabolic activity of all cells within the first $20 \mathrm{~min}$ and survival of most cells [127, 128]. The near complete restoration of ATP and phosphocreatine after ischemia is not associated with restored mitochondrial oxidative metabolism to pre-ischemic levels. The mitochondrial respiration is depressed after neonatal $\mathrm{HI}$ and, after a partial transient recovery, a secondary decrease occurs [129] coinciding with decreased tissue utilization of glucose and activation of apoptosis-related mechanisms, including activation of caspase-3 and DNA fragmentation [130, 131]. This secondary energy failure develops in most brain regions $6-48 \mathrm{~h}$ after the insult in immature animal models [129-131].

Young brains have more apoptotic machinery and neurons often display mixed apoptotic/necrotic morphology after ischemic injury

Some of the apoptotic effectors, such as caspase-3 [132, 133], APAF-1 [134], Bcl-2 [135] and Bax [136], are expressed at higher levels in the developing brain and apoptotic mechanisms seem to be more important in the development of brain injury in the immature than in the adult brain $[132,133,137-$ 142]. Even AIF, where the expression level remains constant during postnatal brain development, is activated to a greater extent in the immature than in the juvenile and adult brain after HI [142, 143]. This seems reasonable in light of the extensive apoptosis taking place during brain development and the large numbers of cells that need to be discretely removed, supporting the notion that embryonic and early postnatal neurons have a greater capacity and readiness to undergo apoptosis. Based on morphological criteria, the initial injury (within a few hours) in the striatum and cortex of neonatal rats was found to be necrosis, but in thalamus the delayed neurodegeneration (within hours to days) was primarily apoptosis, indicating that the morphology of neuronal death is determined by time, region, and potentially by patterns of neuronal connectivity [123]. There are several studies describing dying cells with a mixed morphology, displaying characteristics of both apoptosis and necrosis [144], including after neonatal HI [123-125, 145], further supporting the concept of cross-talk between pathways. The concept of continuum cell death was coined to emphasize that the 


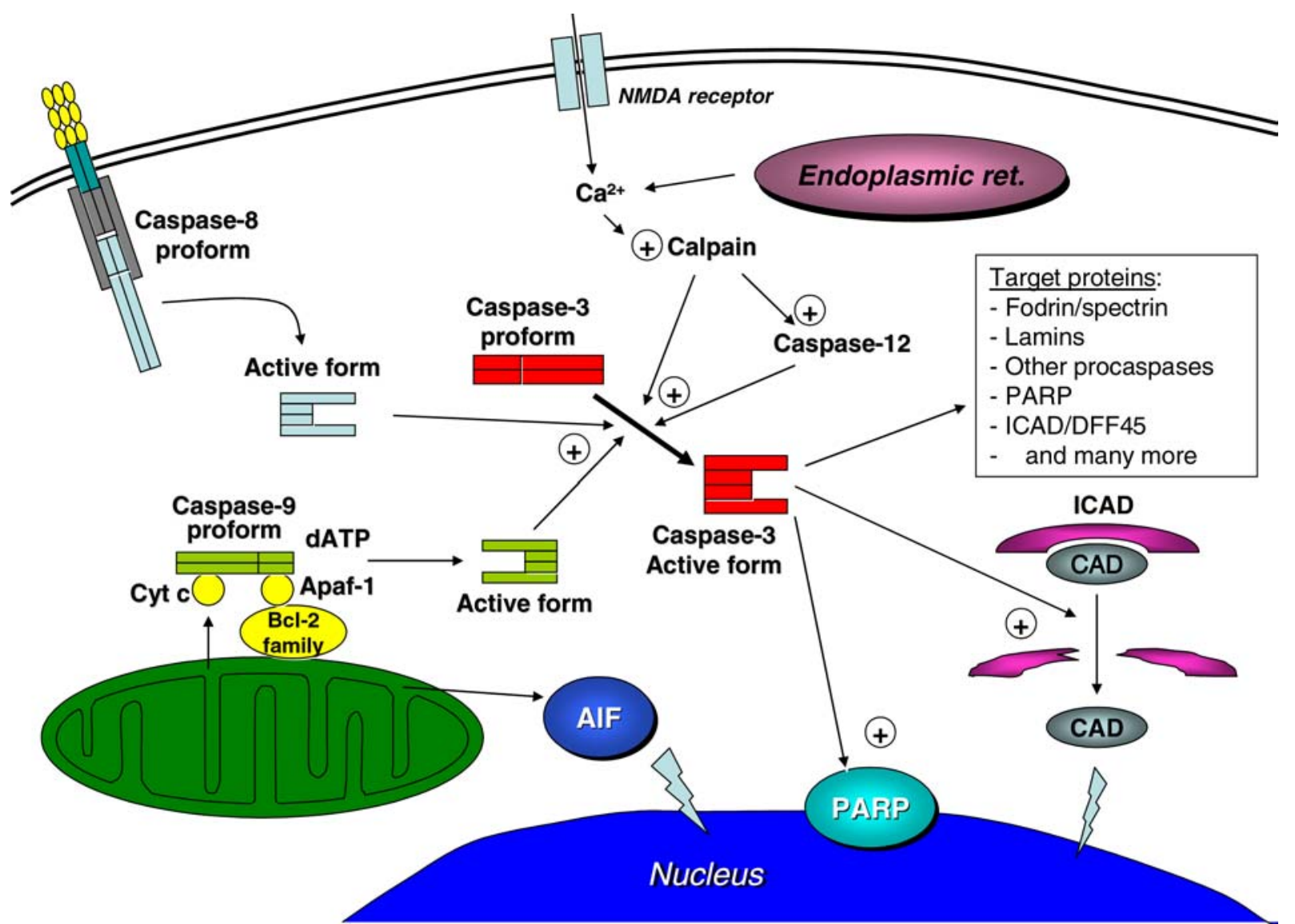

Fig. 2 Schematic representation of the three mechanisms converging on caspase-3, which is the major execution caspase in the brain, particularly in the developing brain. Activated caspase- 3 will cleave a number

of target proteins, including ICAD/DFF45 and PARP, as indicated in the figure. Also indicated is release of the caspase-independent AIF from mitochondria

morphology of dying neurons in the immature brain after HI displayed the full range from necrotic to apoptotic [146]. In Fig. 4 cortical neurons displaying different morphologies after HI can be seen, including necrosis, apoptosis and the mixed pathological apoptosis (Fig. 4).

\section{Extracellular effectors}

Death receptor pathway

Evidence for involvement of the Fas/CD95 receptor and its ligand in ischemic brain injury has been obtained from both the adult and developing brain. After transient focal ischemia in adult rats Fas expression was increased and mice carrying a deficient Fas gene (lpr mice) were less injured than wild type animals (Martin-Villalba 1999). After neonatal rat HI both Fas (Felderhoff-Mueser et al., 2000) and its receptor were upregulated after the insult, in concert with cleavage of procaspase 8 to its active form [147]. Furthermore, mice lacking functional Fas death receptors were protected from
HI brain damage in cortex, striatum, and thalamus [148]. The hippocampus was the only region not protected in these mice, and the selective vulnerability of the hippocampus correlated with lower basal expression of [Fas-associated death-domain-like IL-1beta-converting enzyme]-inhibitory protein (FLIP), and indications of necrosis, as judged by calpain activation and a higher percentage of non-apoptotic morphology was present after HI [148].

\section{Neurotrophins/Cytokines}

Neurotrophins have attracted much attention as potential therapeutic agents after ischemia. BDNF, for example, provided impressive neuroprotection after neonatal (P7) HI [149, 150], but not in older (P21) animals. BDNF treatment produced robust phosphorylation of Trk receptors in $\mathrm{P} 7$ but not $\mathrm{P} 21$ rats, indicating either that the trkB receptors are downregulated with age, or that another factor is missing to mediate the BDNF effects [149]. From the wide range of cytokines only one will be mentioned here, erythropoietin. 


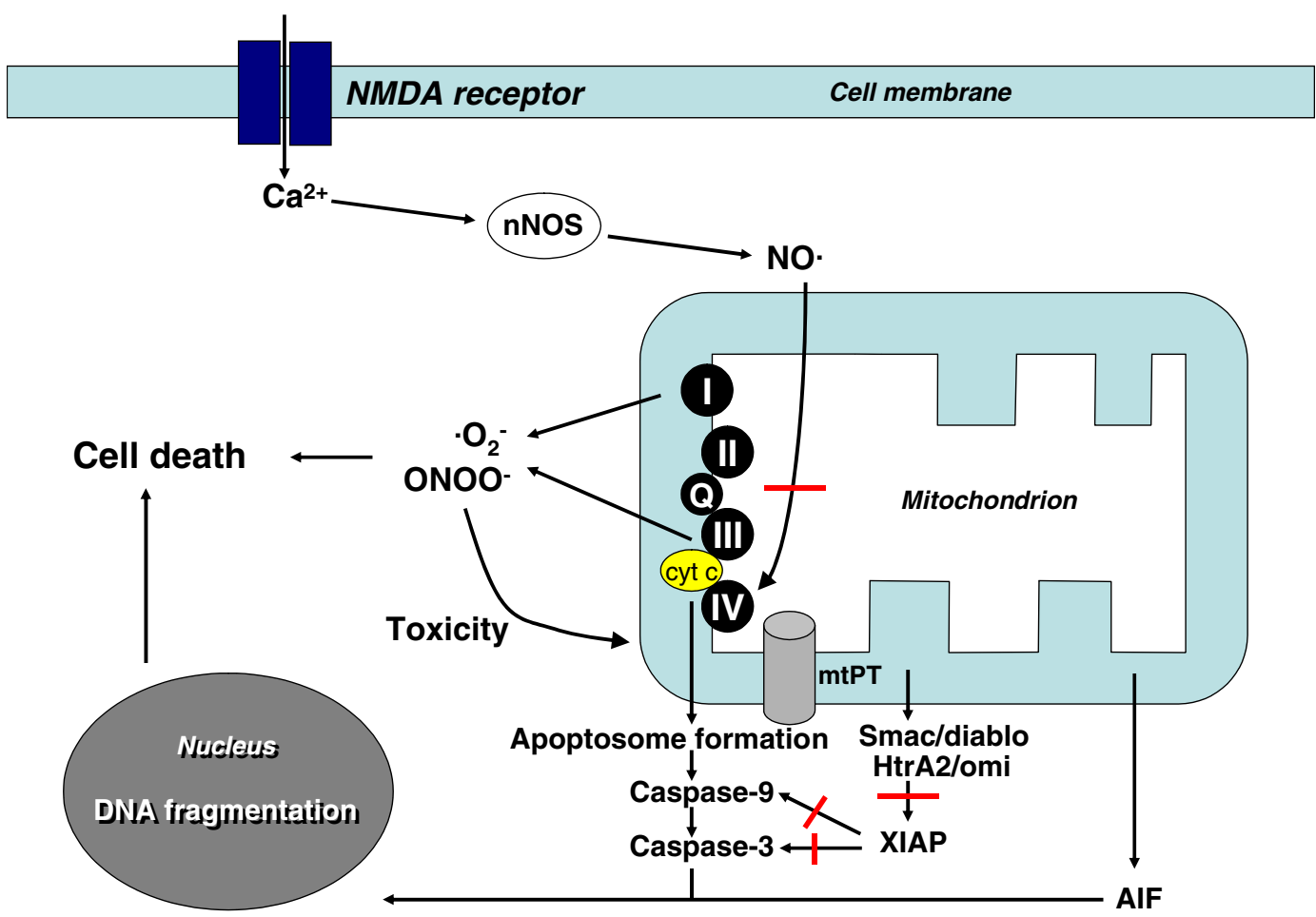

Fig. 3 Mitochondria are a major source of oxygen free radicals, but also a target for free radical attack, promoting mitochondrial permeability transition and release of pro-apoptotic proteins from mitochondria.
Excitotoxic events, leading to calcium influx through NMDA receptors, activates neuronal nitric oxide synthase (nNOS) which may impair oxidative phosphorylation
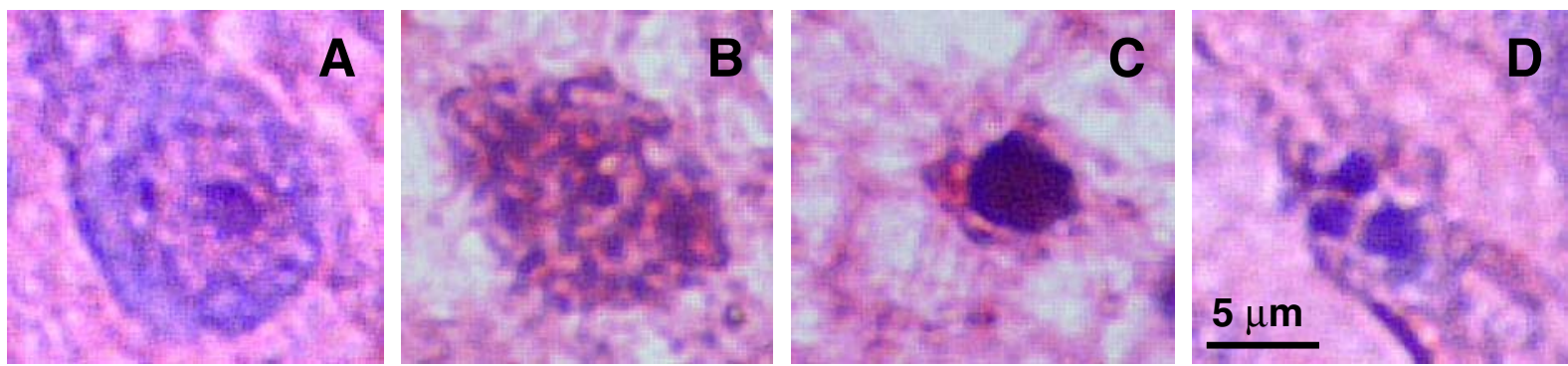

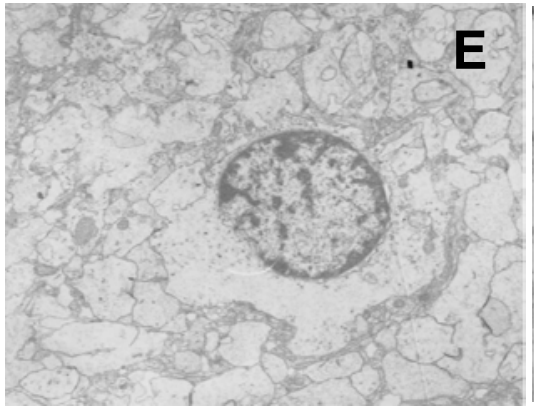

Fig. 4 Microphotographs from neonatal mouse brains after hypoxiaischemia (HI), demonstrating different morphologies in cortical neurons. The upper panels show light microscopic pictures after thionin/fuchsin staining, demonstrating cortical neurons with a morphology typical for (A) a normal cell, (B) necrosis, (C) apoptosis and (D) pathological apoptosis. The lower panels show electron microscopic pictures, demonstrating neurons with a morphology typical for (E) necrosis, $(F)$ apoptosis and $(G)$ pathological apoptosis. Panels A-D: courtesy of Dr. Changlian Zhu, Göteborg University, Sweden. Panels E-G: courtesy of Dr. Frances Northington, Johns Hopkins University, Baltimore, MD, USA 
It has been shown that erythropoietin and non-erythrogenic derivatives by signaling through a non-hematopoietic receptor in the central nervous system afford neuroprotection in various models of brain injury [151-153], including the developing brain [154-156]. Erythropoietin did not, however, prevent radiation-induced loss of precursor cells in the DG or SVZ [122].

\section{Potassium and chloride ion homeostasis}

A universal characteristic of apoptosis is the loss of cell volume or cell shrinkage. While cell shrinkage has traditionally been viewed as a passive event during apoptosis, recent work has shown that the flux of ions associated with the change in cell size plays a critical role in the regulation of the cell death machinery [157]. Apoptotic volume decrease (AVD) has even been shown to be an early prerequisite of apoptosis [158]. Physiological concentrations of potassium prevent death receptor activation, cytochrome $c$ release, apoptosome formation, caspase activation and apoptotic nuclease activity [159-161], at least in lymphocytes, and conversely, loss of intracellular potassium provided conditions compatible with activation of caspases and apoptotic nucleases. Cortical neurons exposed to NMDA in medium containing reduced $\mathrm{Na}^{+}$and $\mathrm{Ca}^{2+}$ (resembling the conditions in ischemic brain tissue) lost substantial intracellular $\mathrm{K}^{+}$and underwent apoptosis. Both $\mathrm{K}^{+}$loss and apoptosis were attenuated by increasing extracellular $\mathrm{K}^{+}$, indicating that NMDA receptor-mediated $\mathrm{K}^{+}$efflux may contribute to neuronal apoptosis after brain ischemia [162]. Furthermore, the $\mathrm{K}^{+}$channel blockers tetraethylammonium (TEA) and clofilium attenuated murine cortical neuronal apoptosis induced by hypoxia in vitro and infarct volume induced by focal ischemia in vivo [163]. In another study, however, neither increased extracellular $\mathrm{K}^{+}$nor the $\mathrm{K}^{+}$channel blocker could prevent staurosporine-induced apoptosis in cultured cortical neurons [164]. The main inhibitory amino acids gamma-aminobutyric acid (GABA) and glycine are excitatory in the developing brain by depolarizing developing neurons that have high intracellular $\mathrm{Cl}^{-}$concentrations and a depolarized $\mathrm{Cl}^{-}$equilibrium potential. GABA becomes inhibitory as net outward neuronal transport of $\mathrm{Cl}^{-}$develops in a caudal-rostral progression. This seems to be of major importance for the wiring of neuronal circuits [165]. Prenatal or neonatal stress, for example hypoxia, can affect the programming of neurotransmitter and receptor expression, which can lead to long-term behavioral effects [166]. The $\mathrm{Na}^{+}-\mathrm{K}^{+}-2 \mathrm{Cl}^{-}$co-transporter (NKCC1) facilitates the accumulation of $\mathrm{Cl}^{-}$in neurons and therefore facilitates seizures in the developing brain, indicating that $\mathrm{NKCC} 1$ inhibitors like bumetanide could be useful in the treatment of neonatal seizures [167].
Intracellular effectors

\section{Caspases}

As mentioned above in the paragraph on secondary energy failure, the mitochondrial respiration is depressed after neonatal $\mathrm{HI}$ and, after a partial transient recovery, a secondary decrease occurs [129] parallel to the decrease of tissue utilization of glucose, loss of MAP-2 immunostaining, activation of caspase-3 and DNA fragmentation [130, 131]. This mitochondrial dysfunction may contribute to or facilitate the release of proapoptotic factors from the intermembrane space of the mitochondria, such as cytochrome $\mathrm{c}$, AIF, endonuclease G, SMAC/Diablo and HtrA2/Omi [168]. Subsequently, caspase-dependent and caspase-independent mechanisms will ensue. Release of Cytochrome $c$ interacts with APAF-1 and dATP/ATP to form the apoptosome, leading to activation of procaspase-9 [169], which in turn cleaves and activates pro-caspase-3, the most abundant effector caspase in the brain. As mentioned above, caspase- 3 expression is strongly regulated with age. Caspase- 3 protein and mRNA in control rat brains decreased more than $80 \%$ from postnatal day 10 to 21 [132], corresponding to when brain growth levels out. The role of the inflammatory caspases (mainly caspase-1, also called IL-1 converting enzyme) in apoptosis is not clear, but they do seem to contribute to brain injury after ischemia through their pro-inflammatory actions. Adult mice lacking the caspase-1 gene (Schielke et al., 1998) or expressing a gene acting as a dominant negative caspase-1 inhibitor under a neuronal promoter (Friedlander et al., 1997) displayed reduced injury after focal ischemia, indicating that neuronal caspase-1 may participate in the cell death process. Similarly, neonatal caspase-1-deficient mice also displayed reduced injury compared with wild type animals, but only if the injury was mild (Liu et al., 1999). Caspase-1 cleaves and activates both IL-1 and IL-18, and neonatal IL-18-deficient mice also showed less brain injury after HI (Hedtjärn et al., 2002).

\section{Differential effects of the endogenous caspase inhibitor XIAP under normal and pathological conditions}

Another finding supporting the concept of pathological apoptosis is that the endogenous caspase inhibitor X-linked Inhibitor of Apoptotosis (XIAP) protein apparently has different effects under physiological and pathological conditions. For example, over-expression of XIAP in neurons did not interfere with physiological neuronal apoptosis, as judged by the normal brain morphology of these mice [122, $170,171]$. In the dentate gyrus (DG), where there is constant neurogenesis and turnover of neurons throughout life, the size and appearance of the DG was not different between wild type and XIAP over-expressing mice. However, 
Fig. 5 A schematic diagram showing the balancing effects of $\mathrm{X}$-linked inhibitor of apoptosis protein (XIAP) under pathological conditions. XIAP can inhibit caspase-3 and caspase- 9 by direct binding to these proteases, but XIAP may also be cleaved by for example caspase-3. HtrA2 and Smac/diablo are released from mitochondria and inhibit XIAP, as does XAF-1. A recently discovered function of XIAP is down-regulation of oxidative stress through up-regulation of the anti-oxidant enzymes SOD2 and TRX2, via NF- $\kappa$ B. The final outcome depends on the relative strength of the cell death mechanisms

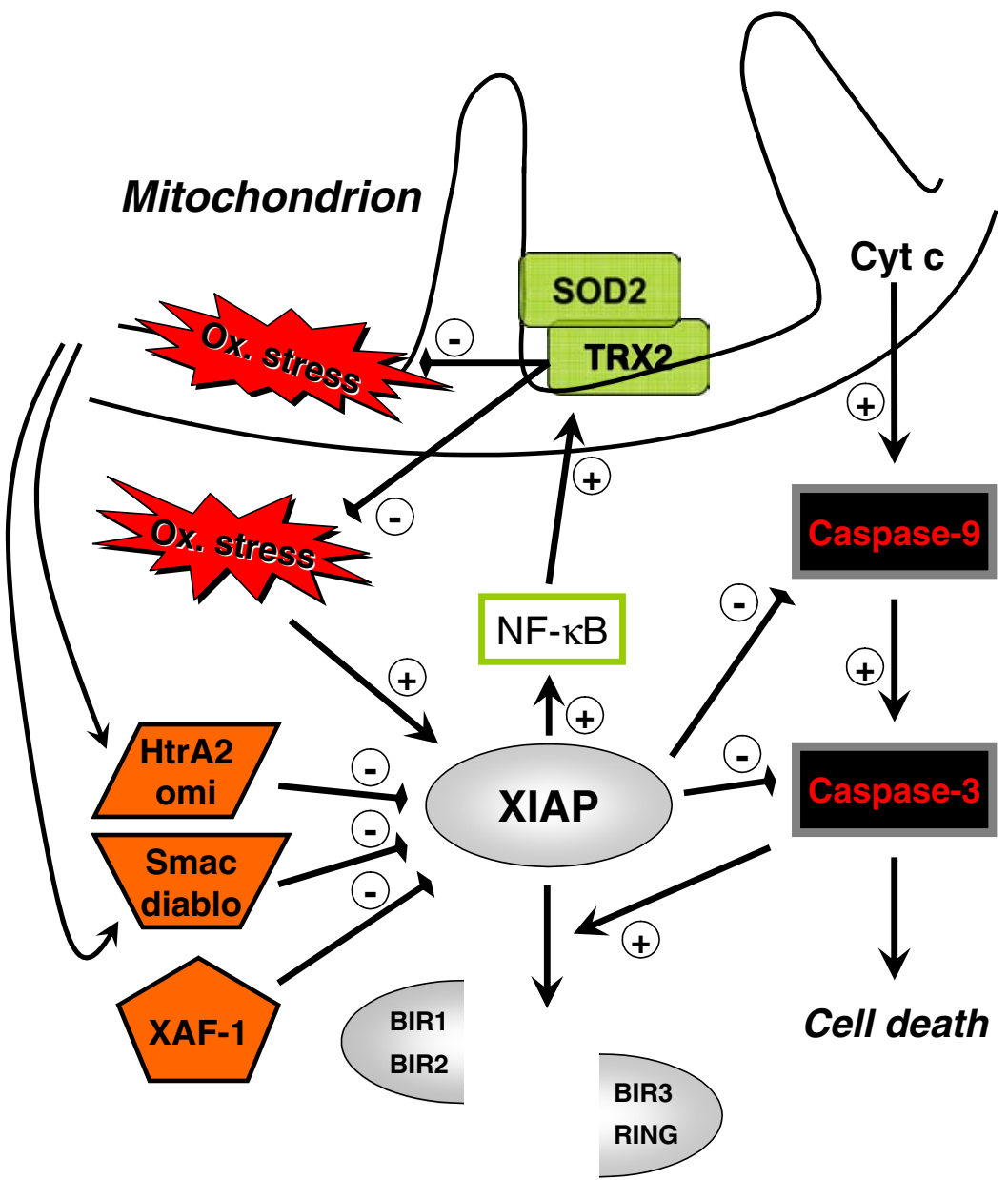

XIAP over-expression did prevent the activation of caspase- 9 and caspase-3 observed after HI [172] and provided significant neuroprotection. Activation of caspase- 9 and caspase- 3 was prevented also in the DG after irradiation [122], but in this paradigm no reduction of cell loss could be observed, so the effects of XIAP were not secondary to tissue protection. Similarly, XIAP was demonstrated to protect against oxidative stress by up-regulating the mitochondrial antioxidant enzymes SOD2 and TRX2 through NF- $\kappa$ B activation after $\mathrm{HI}$ and after irradiation, but not under normal condition, in the absence of an insult (unpublished observations) (Fig. 5). This supports the notion that the same effector can be involved in different pathways and that different regulatory mechanisms are utilized during normal and pathological apoptosis.

\section{Calpains and caspases}

Cross-talk between caspase-3 and calpains, calciumactivated cysteine proteases with a neutral $\mathrm{pH}$ optimum, has been demonstrated. Calpains are cytosolic proteases mainly implicated in excitotoxic cell death and necrosis [173], and calpains, like caspase-3, are also more highly expressed in the immature brain [174]. In mice, calpain-mediated activation of caspase- 3 has been shown to occur by way of caspase-12, such that calpains cleave and release the active form of caspase-12 from the endoplasmic reticulum to the cytosol, where it subsequently can cleave and activate caspase-3 [175] (Fig. 3). After neonatal HI, activation of m-calpain (calpain 2), but not $\mu$-calpain (calpain 1) facilitated the activation of caspase- 3 in a synergistic manner by cleavage in the prodomain of caspase-3, yielding a $29 \mathrm{kDa}$ intermediate form, which apparently was more rapidly processed to the fully active forms [132] (Fig. 2). This is supported by another study demonstrating that $\mathrm{CaCl}_{2}$ triggered nuclear apoptosis and increased caspase- 3 activity in cell-free systems [176], and one study where caspase-3 activation in vivo was decreased in neurons rescued by treatment with the NMDA receptor antagonist MK-801 after HI [177]. This synergistic enhancement of caspase-3 activation after an excitotoxic insult and calpain activation is a prime example of pathological apoptosis, i.e. cross-talk between PCD and mechanisms usually more associated with necrosis. However, there are other reports demonstrating 
calpain-mediated inactivation of caspase. Calpains were shown to cleave APAF-1 in neuroblastoma cells challenged with ionophore, thereby compromising caspase- 3 activation [178]. In one paradigm, non-canonical cleavage of caspase-3 by calcium-dependent proteolysis yielded weak DEVDase activity, but the truncated caspase- 3 thus produced could not be further activated by the cytochrome $c$ and dATP pathway [179]. Also, calpain activation in nitric oxide-triggered excitotoxicity was coupled to execution of caspaseindependent apoptosis in cerebellar granule neurons [180]. Conversely, caspase-3-mediated cleavage of the endogenous calpain inhibitor calpastatin has been demonstrated in several studies [181-183], thereby promoting calpain activation. Neumar et al. demonstrated a dual role for calpains during staurosporine-induced neuronal apoptosis in neuroblastoma cells. In the early execution phase, calpain down-regulated caspase-3-like activity and slowed progression of apoptotic nuclear morphology. Subsequent calpain activity, facilitated by caspase-mediated degradation of calpastatin, contributed to plasma membrane disruption and secondary necrosis [184]. These and other studies project a complex picture of calpain-caspase interaction in cell death, depending on the cell or tissue type studied and the injury paradigm used.

\section{Differential effects of the caspase-independent AIF}

Unlike caspase-3, the caspase-independent ApoptosisInducing Factor (AIF) does not appear to be significantly regulated with age. The AIF protein levels in brain were similar from postnatal day zero to adult [143]. In adult rodents extensive translocation of AIF from mitochondria to nuclei was detected after trauma [185], hypoglycemia [186], focal ischemia [187, 188] and neonatal HI [142, 143, 189]. Extensive and rapid (within $30 \mathrm{~min}$ ) AIF translocation to nuclei after irradiation to the immature brain was also detected in progenitor cells of the dentate gyrus and the subventricular zone, but not in differentiated neurons or glia [122]. In the harlequin $(\mathrm{Hq})$ mouse strain the expression of AIF is reduced to approx. $20 \%$ in adults and $40 \%$ in P9 mice of the wild type level due to a retroviral insertion into the first intron of the AIF gene located on chromosome X [190]. Hq mice displayed $43 \%$ smaller infarcts after adult focal ischemia [191] and $53 \%$ and $43 \%$ infarct volumes in male $\left(\mathrm{YX}^{\mathrm{Hq}}\right)$ and female $\left(\mathrm{X}^{\mathrm{Hq}} \mathrm{X}^{\mathrm{Hq}}\right)$ mice, respectively [192]. Interestingly, AIF activation (as judged by nuclear translocation, was much more prominent in P5 and P9 mice (corresponding to premature and term human brains) than in P21 and P60 mice (corresponding to juvenile and adult human brains), despite the fact that the concentration of AIF was the same at all ages [142]. Again, the same effector displays different roles under different conditions, in this case different developmental levels.
Nitric oxide

Activation of NMDA receptors results in the influx of calcium and subsequent calmodulin-mediated activation of neuronal nitric oxide synthase (nNOS), converting l-arginine to citrulline and nitric oxide (NO) [193] (Fig. 3). NOS activity is high in the postnatal brain, with peak levels preceding the period of maximal synaptogenesis [194]. Both nNOS and, surprisingly, inducible (or macrophage) NOS (iNOS) are constitutively expressed at several-fold higher levels during early postnatal development [142]. Neuronal nitric oxide synthase (nNOS) is expressed in a limited number $(<4 \%)$ of neurons (quisqualate sensitive), but these cells are capable of killing neighboring cells. Elimination of nNOS neurons through injections of quisqualic acid into the cortex of P7 rats rendered these animals resistant to HI [195], and nNOS deficiency through genetic targeting was also neuroprotective [196]. Administration of the combined iNOS/nNOS inhibitor 2-iminobiotin reduced caspase-3 activation [197] and conferred tissue protection [198]. The iNOS inhibitor aminoguanidine [199] (IL-1) also reduced brain injury after $\mathrm{HI}$, further indicating that NO production exerts cytotoxic effects in the developing brain such insults. NO can also mediate neuroprotective actions, through vasodilatation, angiogenesis, inhibition of platelet aggregation and leukocyte activation, explaining why endothelial nitric oxide synthase (eNOS) inhibition resulted in exacerbation of ischemic injury [200]. However, small (or short-lasting) mitochondrial elevations of NO, and subsequently hydrogen peroxide, can trigger protective responses, e.g. stabilization of hypoxia inducible factor-1 alpha, which seems to bring about protective responses also in the immature brain [201]. Also, NO (contrary to peroxynitrite) may exert anti-apoptotic effects through inhibition of cytochrome c release [202] and quenching of excess $\mathrm{O}_{2}$. See also the paragraph on oxidative stress in the section on intracellular effectors below.

\section{Oxidative stress}

There are multiple pathways whereby reactive oxygen species (ROS) are produced in the brain. As mentioned earlier in the preceding paragraph on nitric oxide, NOS activity is a major contributor to generation of free radicals and oxidative stress. Mitochondria are considered to be a major site of ROS production in mammalian cells through electron leakage from the electron transport chain [194, 203], perhaps also after ischemia [204]. Mitochondria also appear to be a major target of ROS attack and the immature brain is particularly susceptible to free radical injury because of its poorly developed scavenging systems and high availability of iron for the catalytic formation of hydroxyl radicals [205]. Formation of ROS in the brain after various insults is respiration-dependent, mitochondria in vitro are sensitive to 
ROS and peroxynitrite, and most data suggest that oxidative stress contributes to the post-ischemic impairment of mitochondrial respiration [206]. When the ROS levels exceed the capacity of the cell in general and the mitochondria in particular to scavenge and render them harmless, the resulting oxidative stress may initiate mitochondrial permeability transition (mtPT) [207], which then in turn potentiates the oxidative stress. Proapoptotic factors are too large to pass directly through the mtPT pore, but opening of the mtPT can trigger the release of cytochrome-c and other intermembrane proteins. In addition, the release of proapoptotic intermembrane proteins may also occur mtPT independent [208]. Thus, oxidative stress can, directly or indirectly, modulate the release of proapoptotic proteins [209-211] and drugs that block the mtPT pore formation, like cyclosporin A, provide neuroprotection in adult models of ischemia, and prevent release of proapoptotic proteins $[212,213]$. In the developing brain, mtPT was demonstrated to occur after HI, as indicated by entrapment of deoxyglucose in mitochondria, but cyclosporin A treatment did not provide neuroprotection after HI using the same, or higher, doses of cyclosporin A as in studies of adult ischemia [214]. It was not shown, however, whether cyclosporin A actually blocked mtPT and the reasons for the lack of protection remain unclear.

Superoxide is dismutated by superoxide dismutase into $\mathrm{H} 2 \mathrm{O} 2$, which is converted to water and oxygen by catalase or glutathione peroxidase. There are three major superoxide dismutases: SOD1 (Cu,Zn-SOD), SOD2 (Mn-SOD) and SOD3 (EC-SOD). SOD1 is mainly found in the cytosolic and lysosomal fractions, but also in the mitochondrial intermembrane space whereas SOD2 is located in the mitochondrial matrix. The neurological outcome and infarctions are aggravated in SOD2-deficient mice after both transient [215] and permanent [216] focal ischemia in adult mice. Conversely, overexpression of SOD2 prevented apoptosis and reduced tissue damage after focal ischemia [217]. SOD1 overexpression in adult mouse brains also reduced the injury after transient focal ischemia [218], but in the immature brain overexpression of SOD1 unexpectedly aggravated the tissue damage after HI [219]. This was subsequently attributed to a limited capacity of the immature brain to convert the accumulated $\mathrm{H}_{2} \mathrm{O}_{2}$ into water and oxygen due to lower levels of catalase and glutathione peroxidase [220], emphasizing the importance of glutathione peroxidase for downstream processing of the $\mathrm{H}_{2} \mathrm{O}_{2}$ produced by SOD.

\section{Autophagy}

Autophagy is a process responsible for the bulk degradation of intracellular material in double or multiple-membrane autophagic vesicles and their delivery to and subsequent degradation by the cell's own lysosomal system. Just like the genetically controlled, physiological PCD, autophagy was demonstrated to be more pronounced during embryonic development and tissue remodeling [221]. It has been suggested that autophagy is a caspase-independent, genetically controlled cell death [222]. Emerging evidence points to the importance of autophagy in the protein quality-control process, a process that may be of particular importance in post-mitotic brain neurons. Loss of Atg 5 or Atg7 (autophagyrelated $5 / 7$ ), two genes essential for autophagy, leads to progressive neurodegeneration, behavioral defects, presence of polyubiquitinated inclusion bodies in neurons and premature death [223, 224]. Visualization of autophagic vesicles by electron microscopy is still the golden standard to demonstrate autophagy. The electrophoretic mobility change of microtubule-associated protein 1, light chain 3 (LC3) from the non-autophagic, cytosolic form (LC3-I; $16 \mathrm{kDa}$ ) to the autophagic, membrane-recruited form (LC3-II; $14 \mathrm{kDa}$ ) provides a molecular marker-based method for detection of autophagic activity [225-228]. LC3-II was higher in the developing, immature mouse brain, compatible with a role for autophagy in brain growth and tissue remodeling [142]. LC3-II inscreased from 1-3 days after HI, coinciding with the peak of cell death and subsequent tissue degeneration, and the LC3-II increase was more pronounced in the adult than in the immature brain [142]. This was the first evidence for ischemia-induced autophagy, providing another example of how cell death mechanisms can be activated by different triggers under normal and pathological conditions. It is unclear at present to what extent autophagy is a cellular repair process, a stress response or actually contributing to cell death.

\section{Challenges for the future}

Pathological apoptosis involves numerous other pathways that could not be addressed here in detail, as this would be beyond the space limitations and scope and of this concise review. Such key players include MAP kinases, heat shock proteins and mechanisms controlling phagocytosis. The challenge for the future will be to unravel whether the respective pathways and mechanisms are (i) directly involved in neurodegeneration/neuroprotection, (ii) only epiphenomena, or (iii) elicited to actually counteract the main process. An illustrative example of the complexity of the issue is the role of JNK in developmental neuronal death, as this MAP kinase promotes apoptosis on one side of the neural tube and blocks it on the other [229]. Another example is the role of phagocytosis that has until recently been considered a cleanup process after damage, but now is known to also take an active part in killing cells during development [230]. The complexity and heterogeneity of brain tissue obviates the need for new and advanced combinations of histology and molecular biology to solve these important questions. 


\section{Summary}

In summary, we argue that the intra- and extracellular conditions after an insult like ischemia or irradiation are not compatible with the execution of normal programmed cell death (PCD). Rather, multiple mechanisms of injury, including apoptotic mechanisms, will be activated and interact on many levels, producing biochemical and morphological characteristics distinctly different from those observed during physiological, developmentally regulated PCD. Often a mixed morphology is observed, with characteristics of both necrotic and apoptotic cell death, particularly after injury to the developing brain, where the apoptotic machinery is more prominent. In view of the large differences compared with physiological PCD, we suggest that cell death occurring after insults like ischemia or irradiation not be called apoptosis. We propose pathological apoptosis as an alternative term, indicating that classical PCD and other cell death mechanisms interact and contribute to the demise of cells.

\section{References}

1. Kerr JFR, Wyllie AH, Currie AR (1972) Apoptosis: a basic biological phenomenon with wide ranging implications in tissue kinetics. Br J Cancer 26:239-257

2. Glucksmann A (1951) Cell deaths in normal vertebrate ontogeny. Biol Rev Camb Phil Soc 26:59-86

3. Hamburger V, Levi-Montalcini R (1949) Proliferation, differentiation and degeneration in the spinal ganglia of the chick embryo under normal and experimental conditions. J Exp Zool 111:457501

4. Oppenheim RW (1991) Cell death during development of the nervous system. Annu Rev Neurosci 14:453-501

5. Meier P, Finch A, Evan G (2000) Apoptosis in development. Nature 407:796-801

6. Kuan CY, Roth KA, Flavell RA et al (2000) Mechanisms of programmed cell death in the developing brain. Trends Neurosci 23:291-297

7. Stadelmann C, Lassmann H (2000) Detection of apoptosis in tissue sections. Cell Tissue Res 301:19-31

8. Gilmore EC, Nowakowski RS, Caviness Jr VS et al (2000) Cell birth, cell death, cell diversity and DNA breaks: how do they all fit together? Trends Neurosci 23:100-105

9. de la Rosa EJ, de Pablo F (2000) Cell death in early neural development: beyond the neurotrophic theory. Trends Neurosci 23:454-458

10. Lockshin RA, Zakeri Z (2001) Programmed cell death and apoptosis: origins of the theory. Nat Rev Mol Cell Biol 2:545-550

11. Snider WD (1994) Functions of the neurotrophins during nervous system development: what the knockouts are teaching us. Cell 77:627-638

12. Davies AM (2003) Regulation of neuronal survival and death by extracellular signals during development. Embo J 22:2537-2545

13. Ernfors P (2001) Local and target-derived actions of neurotrophins during peripheral nervous system development. Cell Mol Life Sci 58:1036-1044

14. Lin LF, Doherty DH, Lile JD et al (1993) GDNF: a glial cell linederived neurotrophic factor for midbrain dopaminergic neurons. Science 260:1130-1132
15. Oo TF, Kholodilov N, Burke RE (2003) Regulation of natural cell death in dopaminergic neurons of the substantia nigra by striatal glial cell line-derived neurotrophic factor in vivo. J Neurosci 23:5141-5148

16. Moore MW, Klein RD, Farinas I et al (1996) Renal and neuronal abnormalities in mice lacking GDNF. Nature 382:76-79

17. Li L, Su Y, Zhao C et al (2006) The role of Ret receptor tyrosine kinase in dopaminergic neuron development. Neuroscience 142(2):391-400

18. Bahr M (2000) Live or let die-retinal ganglion cell death and survival during development and in the lesioned adult CNS. Trends Neurosci 23:483-490

19. Volosin M, Song W, Almeida RD et al (2006) Interaction of survival and death signaling in basal forebrain neurons: roles of neurotrophins and proneurotrophins. J Neurosci 26:7756-7766

20. Harada C, Harada T, Nakamura K et al (2006) Effect of p75NTR on the regulation of naturally occurring cell death and retinal ganglion cell number in the mouse eye. Dev Biol 290:57-65

21. Duenker N, Valenciano AI, Franke A et al (2005) Balance of pro-apoptotic transforming growth factor-beta and anti-apoptotic insulin effects in the control of cell death in the postnatal mouse retina. Eur J Neurosci 22:28-38

22. Lossi L, Mioletti S, Merighi A (2002) Synapse-independent and synapse-dependent apoptosis of cerebellar granule cells in postnatal rabbits occur at two subsequent but partly overlapping developmental stages. Neuroscience 112:509-523

23. Verhage M, Maia AS, Plomp JJ et al (2000) Synaptic assembly of the brain in the absence of neurotransmitter secretion. Science 287:864-869.

24. Ikonomidou C, Bosch F, Miksa M et al (1999) Blockade of NMDA receptors and apoptotic neurodegeneration in the developing brain. Science 283:70-74

25. Ikonomidou C, Bittigau P, Ishimaru MJ et al (2000) Ethanolinduced apoptotic neurodegeneration and fetal alcohol syndrome. Science 287:1056-1060.

26. Ikonomidou C, Stefovska V, Turski L (2000) Neuronal death enhanced by $N$-methyl-D-aspartate antagonists. Proc Natl Acad Sci USA 97:12885-12890.

27. Ikonomidou C, Bittigau $P$, Koch $C$ et al (2001) Neurotransmitters and apoptosis in the developing brain. Biochem Pharmacol 62:401-405

28. Gardoni F, Bellone C, Viviani B et al (2002) Lack of PSD-95 drives hippocampal neuronal cell death through activation of an alpha CaMKII transduction pathway. Eur J Neurosci 16:777-786

29. Mennerick S, Zorumski CF (2000) Neural activity and survival in the developing nervous system. Mol Neurobiol 22:41-54

30. Wang C, Sadovova N, Hotchkiss C et al (2006) Blockade of $N$ methyl- $D$-aspartate receptors by ketamine produces loss of postnatal day 3 monkey frontal cortical neurons in culture. Toxicol Sci 91:192-201

31. Fredriksson A, Archer T, Alm H et al (2004) Neurofunctional deficits and potentiated apoptosis by neonatal NMDA antagonist administration. Behav Brain Res 153:367-376

32. Adams SM, de Rivero Vaccari JC, Corriveau RA (2004) Pronounced cell death in the absence of NMDA receptors in the developing somatosensory thalamus. J Neurosci 24:9441-9450

33. Hardingham GE, Fukunaga Y, Bading H (2002) Extrasynaptic NMDARs oppose synaptic NMDARs by triggering CREB shutoff and cell death pathways. Nat Neurosci 5:405-414

34. Takadera T, Ishida A, Ohyashiki T (2006) Ketamine-induced apoptosis in cultured rat cortical neurons. Toxicol Appl Pharmacol 210:100-107

35. Galli C, Meucci O, Scorziello A et al (1995) Apoptosis in cerebellar granule cells is blocked by high $\mathrm{KCl}$, forskolin, and IGF-1 through distinct mechanisms of action: the involvement of intracellular calcium and RNA synthesis. J Neurosci 15:1172-1179 
36. Kluck RM, McDougall CA, Harmon BV et al (1994) Calcium chelators induce apoptosis-evidence that raised intracellular ionised calcium is not essential for apoptosis. Biochim Biophys Acta 1223:247-254

37. Johnson Jr EM, Koike T, Franklin J (1992) A "calcium set-point hypothesis" of neuronal dependence on neurotrophic factor. Exp Neurol 115:163-166

38. Koike T, Martin DP, Johnson Jr EM (1989) Role of $\mathrm{Ca}^{2+}$ channels in the ability of membrane depolarization to prevent neuronal death induced by trophic-factor deprivation: evidence that levels of internal $\mathrm{Ca}^{2+}$ determine nerve growth factor dependence of sympathetic ganglion cells. Proc Natl Acad Sci USA 86:64216425

39. Groc L, Gustafsson B, Hanse E (2006) AMPA signalling in nascent glutamatergic synapses: there and not there! Trends Neurosci 29:132-139

40. Tashiro A, Sandler VM, Toni N et al (2006) NMDA-receptormediated, cell-specific integration of new neurons in adult dentate gyrus. Nature 442:929-933

41. Hardingham GE, Bading H (2003) The Yin and Yang of NMDA receptor signalling. Trends Neurosci 26:81-89

42. Olney JW, Ikonomidou C, Mosinger JL et al (1989) MK-801 prevents hypobaric-ischemic neuronal degeneration in infant rat brain. J Neurosci 9:1701-1704

43. Hattori H, Morin AM, Schwartz PH et al (1989) Posthypoxic treatment with MK-801 reduces hypoxic-ischemic damage in the neonatal rat. Neurology 39:713-718

44. Hagberg H, Gilland E, Diemer NH et al (1994) Hypoxia-ischemia in the neonatal rat brain: histopathology after post-treatment with NMDA and non-NMDA receptor antagonists. Biol Neonate 66:205-213

45. Wang Y, Ju W, Liu L et al (2004) alpha-Amino-3hydroxy-5-methylisoxazole-4-propionic acid subtype glutamate receptor (AMPAR) endocytosis is essential for $N$-methyl- $D$ aspartate-induced neuronal apoptosis. J Biol Chem 279:4126741270

46. Banks GB, Kanjhan R, Wiese S et al (2005) Glycinergic and GABAergic synaptic activity differentially regulate motoneuron survival and skeletal muscle innervation. J Neurosci 25:1249_ 1259

47. Knuesel I, Elliott A, Chen $\mathrm{HJ}$ et al (2005) A role for synGAP in regulating neuronal apoptosis. Eur J Neurosci 21:611-621

48. Ghoumari AM, Piochon C, Tomkiewicz C et al (2006) Neuroprotective effect of mifepristone involves neuron depolarization. Faseb J 20:1377-1386

49. Arthur DB, Georgi S, Akassoglou K et al (2006) Inhibition of apoptosis by P2Y2 receptor activation: novel pathways for neuronal survival. J Neurosci 26:3798-3804

50. Resta V, Novelli E, Di Virgilio F et al (2005) Neuronal death induced by endogenous extracellular ATP in retinal cholinergic neuron density control. Development 132:2873-2882

51. Raoul C, Pettmann B, Henderson CE (2000) Active killing of neurons during development and following stress: a role for p75(NTR) and Fas? Curr Opin Neurobiol 10:111-117

52. Raoul C, Henderson CE, Pettmann B (1999) Programmed cell death of embryonic motoneurons triggered through the Fas death receptor. J Cell Biol 147:1049-1062

53. Adachi M, Suematsu S, Kondo T et al (1995) Targeted mutation in the Fas gene causes hyperplasia in peripheral lymphoid organs and liver. Nat Genet 11:294-300

54. Watanabe-Fukunaga R, Brannan CI, Copeland NG et al (1992) Lymphoproliferation disorder in mice explained by defects in Fas antigen that mediates apoptosis. Nature 356:314-317

55. Freeman MR (2006) Sculpting the nervous system: glial control of neuronal development. Curr Opin Neurobiol 16:119125
56. Williams ME, Lu X, McKenna WL et al (2006) UNC5A promotes neuronal apoptosis during spinal cord development independent of netrin-1. Nat Neurosci 9:996-998

57. Ben-Zvi A, Yagil Z, Hagalili Y et al (2006) Semaphorin 3A and neurotrophins: a balance between apoptosis and survival signaling in embryonic DRG neurons. J Neurochem 96:585-597

58. Leu ST, Jacques SA, Wingerd KL et al (2004) Integrin alpha4beta1 function is required for cell survival in developing retina. Dev Biol 276:416-430

59. Depaepe V, Suarez-Gonzalez N, Dufour A et al (2005) Ephrin signalling controls brain size by regulating apoptosis of neural progenitors. Nature 435:1244-1250

60. Clarke PGH (1990) Developmental cell death: morphological diversity and multiple mechanisms. Anat Embryol 181:195213

61. Pettmann B, Henderson CE (1998) Neuronal cell death. Neuron 20:633-647

62. Danial NN, Korsmeyer SJ (2004) Cell death: critical control points. Cell 116:205-219

63. Kuida K, Zheng TS, Na S et al (1996) Decreased apoptosis in the brain and premature lethality in CPP32-deficient mice. Nature 384:368-372

64. Kuida K, Haydar TF, Kuan CY et al (1998) Reduced apoptosis and cytochrome c-mediated caspase activation in mice lacking caspase 9. Cell 94:325-337

65. Hakem R, Hakem A, Duncan GS et al (1998) Differential requirement for caspase 9 in apoptotic pathways in vivo. Cell 94(3):339352

66. Oppenheim RW, Flavell RA, Vinsant S et al (2001) Programmed cell death of developing mammalian neurons after genetic deletion of caspases. J Neurosci 21:4752-4760

67. Yoshida H, Kong YY, Yoshida R et al (1998) Apaf1 is required for mitochondrial pathways of apoptosis and brain development. Cell 94:739-750

68. Roth KA, Kuan C, Haydar TF et al (2000) Epistatic and independent functions of caspase-3 and Bcl-X(L) in developmental programmed cell death. Proc Natl Acad Sci USA 97:466-471

69. Lossi L, Tamagno I, Merighi A (2004) Molecular morphology of neuronal apoptosis: analysis of caspase 3 activation during postnatal development of mouse cerebellar cortex. J Mol Histol 35:621-629

70. Chauvier D, Lecoeur H, Langonne A et al (2005) Upstream control of apoptosis by caspase-2 in serum-deprived primary neurons. Apoptosis 10:1243-1259

71. Michaelidis TM, Sendtner M, Cooper JD et al (1996) Inactivation of bcl-2 results in progressive degeneration of motoneurons, sympathetic and sensory neurons during early postnatal development. Neuron 17:75-89

72. Martinou JC, Dubois-Dauphin M, Staple JK et al (1994) Overexpression of BCL-2 in transgenic mice protects neurons from naturally occurring cell death and experimental ischemia. Neuron 13:1017-1030

73. Farlie PG, Dringen R, Rees SM et al (1995) bcl-2 transgene expression can protect neurons against developmental and induced cell death. Proc Natl Acad Sci USA 92:4397-4401

74. Motoyama N, Wang F, Roth KA et al (1995) Massive cell death of immature hematopoietic cells and neurons in Bcl-x-deficient mice. Science 267:1506-1510

75. Knudson CM, Tung KS, Tourtellotte WG et al (1995) Baxdeficient mice with lymphoid hyperplasia and male germ cell death. Science 270:96-99

76. Knudson CM, Korsmeyer SJ (1997) Bcl-2 and Bax function independently to regulate cell death. Nat Genet 16:358-363

77. Sun W, Gould TW, Vinsant S et al (2003) Neuromuscular development after the prevention of naturally occurring neuronal death by Bax deletion. J Neurosci 23:7298-7310 
78. Donovan M, Doonan F, Cotter TG (2006) Decreased expression of pro-apoptotic Bcl-2 family members during retinal development and differential sensitivity to cell death. Dev Biol 291:154169

79. Zekri L, Chebli K, Tourriere $\mathrm{H}$ et al (2005) Control of fetal growth and neonatal survival by the RasGAP-associated endoribonuclease G3BP. Mol Cell Biol 25:8703-8716

80. Silva RM, Ries V, Oo TF et al (2005) CHOP/GADD153 is a mediator of apoptotic death in substantia nigra dopamine neurons in an in vivo neurotoxin model of parkinsonism. J Neurochem 95:974-986

81. Tajiri S, Yano S, Morioka M et al (2006) CHOP is involved in neuronal apoptosis induced by neurotrophic factor deprivation. FEBS Lett 580:3462-3468

82. West AE, Griffith EC, Greenberg ME (2002) Regulation of transcription factors by neuronal activity. Nat Rev Neurosci 3:921931

83. Midorikawa R, Takei Y, Hirokawa N (2006) KIF4 motor regulates activity-dependent neuronal survival by suppressing PARP-1 enzymatic activity. Cell 125:371-383

84. Mason HA, Rakowiecki SM, Gridley T et al (2006) Loss of notch activity in the developing central nervous system leads to increased cell death. Dev Neurosci 28:49-57

85. Oishi K, Kamakura S, Isazawa Y et al (2004) Notch promotes survival of neural precursor cells via mechanisms distinct from those regulating neurogenesis. Dev Biol 276:172-184

86. Jacobs WB, Govoni G, Ho D et al (2005) p63 is an essential proapoptotic protein during neural development. Neuron 48:743756

87. Jiang Y, de Bruin A, Caldas $\mathrm{H}$ et al (2005) Essential role for survivin in early brain development. J Neurosci 25:6962-6970

88. Copani A, Uberti D, Sortino MA et al (2001) Activation of cellcycle-associated proteins in neuronal death: a mandatory or dispensable path? Trends Neurosci 24:25-31

89. Ross ME (1996) Cell division and the nervous system: regulating the cycle from natural differentiation to death. Trends Neurosci 19:62-68

90. ElShamy WM, Fridvall LK, Ernfors P (1998) Growth arrest failure, G1 restriction point override, and $\mathrm{S}$ phase death of sensory precursor cells in the absence of neurotrophin-3. Neuron 21:1003-1015

91. Taylor AR, Prevette D, Urioste AS et al (2003) Cell cycle events distinguish sensory neuronal death from motoneuron death as a result of trophic factor deprivation. Mol Cell Neurosci 24:323339

92. Sakai K, Suzuki K, Tanaka S et al (1999) Up-regulation of cyclin D1 occurs in apoptosis of immature but not mature cerebellar granule neurons in culture. J Neurosci Res 58:396-406

93. Groc L, Bezin L, Jiang H et al (2001) Bax, Bcl-2 and cyclin expression and apoptosis in rat substantia nigra during development. Neurosci Lett 306:198-202

94. Droge W (2002) Free radicals in the physiological control of cell function. Physiol Rev 82:47-95

95. Greenlund LJS, Korsmeyer SJ, Johnson Jr EM (1995) Role of bcl-2 in the survival and function of developing and mature sympathetic neurons. Neuron 15:649-661

96. Greenlund LJS, Deckwerth TL, Johnson Jr EM (1995) Superoxide dismutase delays neuronal apoptosis: a role for reactive oxygen species in programmed neuronal death. Neuron 14:303-315

97. Castagne V, Clarke PGH (1996) Axotomy-induced retinal ganglion cell death in development: its time-course and its diminution by antioxidants. Proc R Soc Lond 263:1193-1197

98. Castagne V, Gautschi M, Lefevre K et al (1999) Relationships between neuronal death and the cellular redox status. Focus on the developing nervous system. Prog Neurobiol 59:397-423

99. Castro-Obregon S, Covarrubias L (1996) Role of retinoic acid and oxidative stress in embryonic stem cell death and neuronal differentiation. FEBS Lett 381:93-97

100. Kane DJ, Sarafian TA, Anton R et al (1993) Bcl-2 inhibition of neural death: decreased generation of reactive oxygen species. Science 262:1274-1277

101. Estevez AG, Spear N, Manuel SM et al (1998) Nitric oxide and superoxide contribute to motor neuron apoptosis induced by trophic factor deprivation. J Neurosci 18:923-931

102. Sanchez-Carbente MR, Castro-Obregon S, Covarrubias L et al (2005) Motoneuronal death during spinal cord development is mediated by oxidative stress. Cell Death Differ 12:279-291

103. Cadet JL, Brannock C (1998) Free radicals and the pathobiology of brain dopamine systems. Neurochem Int 32:117-131

104. Roy E, Bedard PJ (1993) L-Deprenyl increases survival of rat foetal nigral neurones in culture. Neuroreport 4:1183-1186

105. Tatton WG, Ju WY, Holland DP et al (1994) (-)-Deprenyl reduces PC12 cell apoptosis by inducing new protein synthesis. J Neurochem 63:1572-1575

106. Finberg JPM, Takeshima T, Johnston JM et al (1998) Increased survival of dopaminergic neurons by rasagiline, a monoamine oxidase B inhibitor. Neuroreport 9:703-707

107. Park DS, Morris EJ, Stefanis L et al (1998) Multiple pathways of neuronal death induced by DNA-damaging agents, NGF deprivation, and oxidative stress. J Neurosci 18:830-840

108. Stull ND, Polan DP, Iacovitti L (2002) Antioxidant compounds protect dopamine neurons from death due to oxidative stress in vitro. Brain Res 931:181-185

109. Lui PW, Suen KC, Chan YS et al (2003) Striatal neurons but not nigral dopaminergic neurons in neonatal primary cell culture express endogenous functional $N$-methyl- $D$-aspartate receptors. Brain Res Mol Brain Res 120:9-21

110. Lin JY, Lipski J (2001) Dopaminergic substantia nigra neurons express functional nmda receptors in postnatal rats. J Neurophysiol 85:1336-1339.

111. Janec E, Burke RE (1993) Naturally occuring cell death during postnatal development of the substantia nigra pars compacta of rat. Mol Cell Neurosci 4:30-35

112. Oo TF, Burke RE (1997) The time course of developmental cell death in phenotypically defined dopaminergic neurons of the substantia nigra. Dev Brain Res 98:191-196

113. Groc L, Levine RA, Foster JA et al (2000) Evidence of deprenylinsensitive apoptosis of nigral dopamine neurons during development. Brain Res Dev Brain Res 120:95-98.

114. Groc L, Bezin L, Foster JA et al (2001) Lipid peroxidationmediated oxidative stress and dopamine neuronal apoptosis in the substantia nigra during development. Neurochem Int 39:127133

115. Groc L, Jackson Hunter T, Jiang $\mathrm{H}$ et al (2002) Nitric oxide synthase inhibition during development: effect on apoptotic death of dopamine neurons. Brain Res Dev Brain Res 138:147153

116. Anastasiadis PZ, Jiang H, Bezin L et al (2001) Tetrahydrobiopterin enhances apoptotic PC12 cell death following withdrawal of trophic support. J Biol Chem 276:9050-9058.

117. Zhang Y, Zhang J, Zhao B (2004) Nitric oxide synthase inhibition prevents neuronal death in the developing visual cortex. Eur J Neurosci 20:2251-2259

118. Tsatmali M, Walcott EC, Crossin KL (2005) Newborn neurons acquire high levels of reactive oxygen species and increased mitochondrial proteins upon differentiation from progenitors. Brain Res 1040:137-150

119. Groc L, Hunter TJ, Jiang H et al (2003) Developmental cell death and oxidative stress: lessons from nigral dopamine neurons. Ann NY Acad Sci 991:307-310

120. Jacobson MD (1996) Reactive oxygen species and programmed cell death. Trends Biochem Sci 21:83-86 
121. Nicotera P, Leist M, Manzo L (1999) Neuronal cell death: a demise with different shapes. Trends Pharmacol Sci 20:46-51

122. Fukuda H, Fukuda A, Zhu C et al (2004) Irradiation-induced progenitor cell death in the developing brain is resistant to erythropoietin treatment and caspase inhibition. Cell Death Differ 11:1166-1178

123. Northington FJ, Ferriero DM, Graham EM et al (2001) Early Neurodegeneration after Hypoxia-Ischemia in Neonatal Rat Is Necrosis while Delayed Neuronal Death Is Apoptosis. Neurobiol Dis 8:207-219

124. Puka-Sundvall M, Gajkowska B, Cholewinski M et al (2000) Subcellular distribution of calcium and ultrastructural changes after cerebral hypoxia-ischemia in immature rats. Brain Res Dev Brain Res 125:31-41

125. Liu CL, Siesjo BK, Hu BR (2004) Pathogenesis of hippocampal neuronal death after hypoxia-ischemia changes during brain development. Neuroscience 127:113-123

126. Siesjo BK (1992) Pathophysiology and treatment of focal cerebral ischemia. Part I: Pathophysiology. J Neurosurg 77:169-184

127. Nowak Jr TS, Fried RL, Lust WD et al (1985) Changes in brain energy metabolism and protein synthesis following transient bilateral ischemia in the gerbil. J Neurochem 44:487-494

128. Pulsinelli WA, Duffy TE (1983) Regional energy balance in rat brain after transient forebrain ischemia. J Neurochem 40:15001503

129. Lorek A, Takei Y, Cady EB et al (1994) Delayed ("secondary”) cerebral energy failure after acute hypoxia-ischemia in the newborn piglet: continuous 48-hour studies by phosphorus magnetic resonance spectroscopy. Pediatr Res 36:699-706

130. Gilland E, Puka-Sundvall M, Hillered L et al (1998) Mitochondrial function and energy metabolism after hypoxia-ischemia in the immature rat brain: involvement of NMDA-receptors. J Cereb Blood Flow Metab 18:297-304

131. Puka-Sundvall M, Wallin C, Gilland E et al (2000) Impairment of mitochondrial respiration after cerebral hypoxia-ischemia in immature rats: relationship to activation of caspase- 3 and neuronal injury. Brain Res Dev Brain Res 125:43-50

132. Blomgren K, Zhu C, Wang X et al (2001) Synergistic activation of caspase- 3 by m-calpain after neonatal hypoxia-ischemia: a mechanism of "pathological apoptosis"? J Biol Chem 276:1019110198

133. Ni B, Wu X, Su Y et al (1998) Transient global forebrain ischemia induces a prolonged expression of the caspase- 3 mRNA in rat hippocampal CA1 pyramidal neurons. J Cereb Blood Flow Metab $18: 248-256$

134. Ota K, Yakovlev AG, Itaya A et al (2002) Alteration of Apoptotic Protease-Activating Factor-1 (APAF-1)-Dependent Apoptotic Pathway During Development of Rat Brain and Liver. J Biochem (Tokyo) 131:131-135

135. Merry DE, Veis DJ, Hickey WF et al (1994) bcl-2 protein expression is widespread in the developing nervous system and retained in the adult PNS. Development 120:301-311

136. Vekrellis K, McCarthy MJ, Watson A et al (1997) Bax promotes neuronal cell death and is downregulated during the development of the nervous system. Development 124:1239-1249

137. Hu BR, Liu CL, Ouyang Y et al (2000) Involvement of caspase-3 in cell death after hypoxia-ischemia declines during brain maturation. J Cereb Blood Flow Metab 20:1294-1300

138. Gill R, Soriano M, Blomgren K et al (2002) Role of caspase3 activation in cerebral ischemia-induced neurodegeneration in adult and neonatal brain. J Cereb Blood Flow Metab 22:420430

139. Cheng Y, Deshmukh M, D'Costa A et al (1998) Caspase inhibitor affords neuroprotection with delayed administration in a rat model of neonatal hypoxic-ischemic brain injury. J Clin Invest 101:1992-1999
140. Han BH, Xu D, Choi J et al (2002) Selective, reversible caspase-3 inhibitor is neuroprotective and reveals distinct pathways of cell death after neonatal hypoxic-ischemic brain injury. J Biol Chem 277:30128-30136

141. Mehmet H, Yue X, Squier MV et al (1994) The relationship between impaired cerebral energy metabolism and apoptosis in the cingulate gyrus of newborn piglets following transient hypoxia-ischaemia. UCL/RPMS Perinatal Brain Research Group. Biochem Soc Trans 22:421S

142. Zhu C, Wang X, Xu F et al (2005) The influence of age on apoptotic and other mechanisms of cell death after cerebral hypoxiaischemia. Cell Death Differ 12:162-176

143. Zhu C, Qiu L, Wang X et al (2003) Involvement of apoptosisinducing factor in neuronal death after hypoxia-ischemia in the neonatal rat brain. J Neurochem 86:306-317

144. Leist M, Jäättelä M (2001) Four deaths and a funeral: from caspases to alternative mechanisms. Nat Rev Mol Cell Biol 2:589598

145. Nakajima W, Ishida A, Lange MS et al (2000) Apoptosis has a prolonged role in the neurodegeneration after hypoxic ischemia in the newborn rat. J Neurosci 20:7994-8004

146. Portera-Cailliau C, Price DL, Martin LJ (1997) J Comp Neurol 378(1):88-104

147. Northington FJ, Ferriero DM, Flock DL et al (2001) Delayed neurodegeneration in neonatal rat thalamus after hypoxia-ischemia is apoptosis. J Neurosci 21:1931-1938.

148. Graham EM, Sheldon RA, Flock DL et al (2004) Neonatal mice lacking functional Fas death receptors are resistant to hypoxicischemic brain injury. Neurobiol Dis 17:89-98

149. Cheng Y, Gidday JM, Yan Q et al (1997) Marked age-dependent neuroprotection by brain-derived neurotrophic factor against neonatal hypoxic-ischemic brain injury. Ann Neurol 41:521-529

150. Han BH, Holtzman DM (2000) BDNF protects the neonatal brain from hypoxic-ischemic injury in vivo via the ERK pathway. J Neurosci 20:5775-5781

151. Leist M, Ghezzi P, Grasso G et al (2004) Derivatives of erythropoietin that are tissue protective but not erythropoietic. Science 305:239-242

152. Erbayraktar S, Grasso G, Sfacteria A et al (2003) Asialoerythropoietin is a nonerythropoietic cytokine with broad neuroprotective activity in vivo. Proc Natl Acad Sci USA 100:6741-6746

153. Villa P, van Beek J, Larsen AK et al (2006) Reduced functional deficits, neuroinflammation, and secondary tissue damage after treatment of stroke by nonerythropoietic erythropoietin derivatives. J Cereb Blood Flow Metab 2006 Jul 12; [Epub ahead of print] $1-12$

154. Wang X, Zhu C, Wang X et al (2004) The nonerythropoietic asialoerythropoietin protects against neonatal hypoxia-ischemia as potently as erythropoietin. J Neurochem 91:900-910

155. Matsushita H, Johnston MV, Lange MS et al (2003) Protective effect of erythropoietin in neonatal hypoxic ischemia in mice. Neuroreport 14:1757-1761

156. Sun Y, Zhou C, Polk P et al (2004) Mechanisms of erythropoietininduced brain protection in neonatal hypoxia-ischemia rat model. J Cereb Blood Flow Metab 24:259-270

157. Bortner CD, Cidlowski JA (2004) The role of apoptotic volume decrease and ionic homeostasis in the activation and repression of apoptosis. Pflugers Arch 448:313-318

158. Maeno E, Ishizaki Y, Kanaseki T et al (2000) Normotonic cell shrinkage because of disordered volume regulation is an early prerequisite to apoptosis. Proc Natl Acad Sci USA 97:9487-9492

159. Cain K, Langlais C, Sun XM et al (2001) Physiological concentrations of $\mathrm{K}+$ inhibit cytochrome c-dependent formation of the apoptosome. J Biol Chem 276:41985-41990

160. Thompson GJ, Langlais C, Cain K et al (2001) Elevated extracellular $\mathrm{K}+$. inhibits death-receptor- and chemical-mediated 
apoptosis prior to caspase activation and cytochrome $c$ release. Biochem J 357:137-145

161. Hughes Jr FM, Bortner CD, Purdy GD et al (1997) Intracellular $\mathrm{K}+$ suppresses the activation of apoptosis in lymphocytes. J Biol Chem 272:30567-30576

162. Yu SP, Yeh C, Strasser U et al (1999) NMDA receptor-mediated $\mathrm{K}+$ efflux and neuronal apoptosis. Science 284:336-339

163. Wei L, Yu SP, Gottron F et al (2003) Potassium channel blockers attenuate hypoxia- and ischemia-induced neuronal death in vitro and in vivo. Stroke 34:1281-1286

164. Small DL, Tauskela J, Xia Z (2002) Role for chloride but not potassium channels in apoptosis in primary rat cortical cultures. Neurosci Lett 334:95-98

165. Ben-Ari Y (2002) Excitatory actions of gaba during development: the nature of the nurture. Nat Rev Neurosci 3:728-739

166. Herlenius E, Lagercrantz H (2004) Development of neurotransmitter systems during critical periods. Exp Neurol 190(Suppl 1): S8-S21

167. Dzhala VI, Talos DM, Sdrulla DA et al (2005) NKCC1 transporter facilitates seizures in the developing brain. Nat Med 11:12051213

168. Ravagnan L, Roumier T, Kroemer G (2002) Mitochondria, the killer organelles and their weapons. J Cell Physiol 192:131-137

169. Acehan D, Jiang X, Morgan DG et al (2002) Threedimensional structure of the apoptosome: implications for assembly, procaspase-9 binding, and activation. Mol Cell 9:423-432

170. Trapp T, Korhonen L, Besselmann M et al (2003) Transgenic mice overexpressing XIAP in neurons show better outcome after transient cerebral ischemia. Mol Cell Neurosci 23:302-313

171. Wang X, Zhu C, Wang X et al (2004) X-linked inhibitor of apoptosis (XIAP) protein protects against caspase activation and tissue loss after neonatal hypoxia-ischemia. Neurobiol Dis 16:179189

172. Wang X, Zhu C, Hagberg $\mathrm{H}$ et al (2004) X-linked inhibitor of apoptosis (XIAP) protein protects against caspase activation and tissue loss after neonatal hypoxia-ischemia. Neurobiol Dis 16:179-189

173. Huang Y, Wang KK (2001) The calpain family and human disease. Trends Mol Med 7:355-362.

174. Blomgren K, Karlsson JO (1989) Developmental changes of calpain and calpastatin in rabbit brain. Neurochem Res 14:11491152.

175. Nakagawa T, Zhu H, Morishima N et al (2000) Caspase-12 mediates endoplasmic-reticulum-specific apoptosis and cytotoxicity by amyloid-beta. Nature 403:98-103

176. Juin P, Pelletier M, Oliver L et al (1998) Induction of a caspase3-like activity by calcium in normal cytosolic extracts triggers nuclear apoptosis in a cell-free system. J Biol Chem 273:1755917564

177. Puka-Sundvall M, Hallin U, Zhu C et al (2000) NMDA blockade attenuates caspase-3 activation and DNA fragmentation after neonatal hypoxia-ischemia. Neuroreport 11:2833-2836.

178. Reimertz C, Kogel D, Lankiewicz S et al (2001) Ca(2+)-induced inhibition of apoptosis in human SH-SY5Y neuroblastoma cells: degradation of apoptotic protease activating factor-1 (APAF-1). J Neurochem 78:1256-1266

179. Pelletier M, Oliver L, Meflah K et al (2005) Caspase-3 can be pseudo-activated by a $\mathrm{Ca}^{2+}$-dependent proteolysis at a noncanonical site. FEBS Lett 579:2364-2368

180. Volbracht C, Chua BT, Ng CP et al (2005) The critical role of calpain versus caspase activation in excitotoxic injury induced by nitric oxide. J Neurochem 93:1280-1292

181. Pörn-Ares MI, Samali A, Orrenius S (1998) Cleavage of the calpain inhibitor, calpastatin, during apoptosis. Cell Death Differ 5:1028-1033

182. Wang KK, Posmantur R, Nadimpalli R et al (1998) Caspase- mediated fragmentation of calpain inhibitor protein calpastatin during apoptosis. Arch Biochem Biophys 356:187-196

183. Blomgren K, Hallin U, Andersson AL et al (1999) Calpastatin is up-regulated in response to hypoxia and is a suicide substrate to calpain after neonatal cerebral hypoxia-ischemia. J Biol Chem 274:14046-14052.

184. Neumar RW, Xu YA, Gada H et al (2003) Cross-talk between calpain and caspase proteolytic systems during neuronal apoptosis. J Biol Chem 278:14162-14167

185. Zhang X, Chen J, Graham SH et al (2002) Intranuclear localization of apoptosis-inducing factor (AIF) and large scale DNA fragmentation after traumatic brain injury in rats and in neuronal cultures exposed to peroxynitrite. J Neurochem 82:181191

186. Ferrand-Drake M, Zhu C, Gido G et al (2003) Cyclosporin A prevents calpain activation despite increased intracellular calcium concentrations, as well as translocation of apoptosisinducing factor, cytochrome $\mathrm{c}$ and caspase- 3 activation in neurons exposed to transient hypoglycemia. J Neurochem 85:14311442

187. Cao G, Clark RS, Pei W et al (2003) Translocation of apoptosisinducing factor in vulnerable neurons after transient cerebral ischemia and in neuronal cultures after oxygen-glucose deprivation. J Cereb Blood Flow Metab 23:1137-1150

188. Plesnila N, Zhu C, Culmsee C et al (2004) Nuclear translocation of apoptosis-inducing factor after focal cerebral ischemia. J Cereb Blood Flow Metab 24:458-466

189. Zhu C, Xu F, Wang X et al (2006) Different apoptotic mechanisms are activated in male and female brains after neonatal hypoxiaischaemia. J Neurochem 96:1016-1027

190. Klein JA, Longo-Guess CM, Rossmann MP et al (2002) The harlequin mouse mutation downregulates apoptosis-inducing factor. Nature 419:367-374

191. Culmsee C, Zhu C, Landshamer S et al (2005) Apoptosis-inducing factor triggered by poly(ADP-ribose) polymerase and Bid mediates neuronal cell death after oxygen-glucose deprivation and focal cerebral ischemia. J Neurosci 25:10262-10272

192. Zhu C, Wang X, Huang Z et al (2006) Apoptosis-inducing factor is a major contributor to neuronal loss induced by neonatal cerebral hypoxia-ischemia. Cell Death Differ 2006 Oct 13; [Epub ahead of print] $1-10$

193. Dawson VL, Dawson TM (1996) Nitric oxide neurotoxicity. J Chem Neuroanat 10:179-190

194. Lizasoain I, Weiner CP, Knowles RG et al (1996) The ontogeny of cerebral and cerebellar nitric oxide synthase in the guinea pig and rat. Pediatr Res 39:779-783

195. Ferriero DM, Sheldon RA, Black SM et al (1995) Selective destruction of nitric oxide synthase neurons with quisqualate reduces damage after hypoxia-ischemia in the neonatal rat. Pediatr Res 38:912-918

196. Ferriero DM, Holtzman DM, Black SM et al (1996) Neonatal mice lacking neuronal nitric oxide synthase are less vulnerable to hypoxic-ischemic injury. Neurobiol Dis 3:64-71

197. Zhu C, Wang X, Qiu L et al (2004) Nitrosylation precedes caspase-3 activation and translocation of apoptosis-inducing factor in neonatal rat cerebral hypoxia-ischaemia. J Neurochem 90:462-471

198. Peeters-Scholte C, Koster J, Veldhuis W et al (2002) Neuroprotection by selective nitric oxide synthase inhibition at 24 hours after perinatal hypoxia-ischemia. Stroke 33:2304-2310

199. Thoresen M, Satas S, Puka-Sundvall M et al (1997) Post-hypoxic hypothermia reduces cerebrocortical release of NO and excitotoxins. Neuroreport 8:3359-3362

200. Huang Z, Huang PL, Panahian N et al (1994) Effects of cerebral ischemia in mice deficient in neuronal nitric oxide synthase. Science 265:1883-1885 
201. Sharp FR, Bernaudin M (2004) HIF1 and oxygen sensing in the brain. Nat Rev Neurosci 5:437-448

202. Brookes PS, Levonen AL, Shiva S et al (2002) Mitochondria: regulators of signal transduction by reactive oxygen and nitrogen species. Free Radic Biol Med 33:755-764

203. Turrens JF (2003) Mitochondrial formation of reactive oxygen species. J Physiol 552:335-344

204. Piantadosi CA, Zhang J (1996) Mitochondrial generation of reactive oxygen species after brain ischemia in the rat. Stroke 27:327331; discussion 332

205. Blomgren K, Hagberg H (2006) Free radicals, mitochondria, and hypoxia-ischemia in the developing brain. Free Radic Biol Med 40:388-397

206. Fiskum G, Murphy AN, Beal MF (1999) Mitochondria in neurodegeneration: acute ischemia and chronic neurodegenerative diseases. J Cereb Blood Flow Metab 19:351-369

207. Vieira HL, Belzacq AS, Haouzi D et al (2001) The adenine nucleotide translocator: a target of nitric oxide, peroxynitrite, and 4-hydroxynonenal. Oncogene 20:4305-4316

208. Kobayashi T, Kuroda S, Tada M et al (2003) Calcium-induced mitochondrial swelling and cytochrome $\mathrm{c}$ release in the brain: its biochemical characteristics and implication in ischemic neuronal injury. Brain Res 960:62-70

209. Fujimura M, Morita-Fujimura Y, Noshita N et al (2000) The cytosolic antioxidant copper/zinc-superoxide dismutase prevents the early release of mitochondrial cytochrome $c$ in ischemic brain after transient focal cerebral ischemia in mice. J Neurosci 20:2817-2824

210. Morita-Fujimura Y, Fujimura M, Yoshimoto T et al (2001) Superoxide during reperfusion contributes to caspase-8 expression and apoptosis after transient focal stroke. Stroke 32:2356-2361

211. Sugawara T, Noshita N, Lewen A et al (2002) Overexpression of copper/zinc superoxide dismutase in transgenic rats protects vulnerable neurons against ischemic damage by blocking the mitochondrial pathway of caspase activation. J Neurosci 22:209-217

212. Matsumoto S, Friberg H, Ferrand-Drake M et al (1999) Blockade of the mitochondrial permeability transition pore diminishes infarct size in the rat after transient middle cerebral artery occlusion. J Cereb Blood Flow Metab 19:736-741

213. Yoshimoto T, Siesjo BK (1999) Posttreatment with the immunosuppressant cyclosporin A in transient focal ischemia. Brain Res 839:283-291

214. Puka-Sundvall M, Gilland E, Hagberg H (2001) Cerebral hypoxia-ischemia in immature rats: involvement of mitochondrial permeability transition? Dev Neurosci 23:192-197

215. Kim GW, Kondo T, Noshita N et al (2002) Manganese superoxide dismutase deficiency exacerbates cerebral infarction after focal cerebral ischemia/reperfusion in mice: implications for the production and role of superoxide radicals. Stroke 33:809-815

216. Murakami K, Kondo T, Kawase Met al (1998) Mitochondrial susceptibility to oxidative stress exacerbates cerebral infarction that follows permanent focal cerebral ischemia in mutant mice with manganese superoxide dismutase deficiency. J Neurosci 18:205213

217. Keller JN, Kindy MS, Holtsberg FW et al (1998) Mitochondrial manganese superoxide dismutase prevents neural apoptosis and reduces ischemic brain injury: suppression of peroxynitrite production, lipid peroxidation, and mitochondrial dysfunction. J Neurosci 18:687-697

218. Yang G, Chan PH, Chen J et al (1994) Human copper-zinc superoxide dismutase transgenic mice are highly resistant to reperfusion injury after focal cerebral ischemia. Stroke 25:165-170

219. Ditelberg JS, Sheldon RA, Epstein CJ et al (1996) Brain injury after perinatal hypoxia-ischemia is exacerbated in copper/zinc superoxide dismutase transgenic mice. Pediatr Res 39:204208

220. Fullerton HJ, Ditelberg JS, Chen SF et al (1998) Copper/zinc superoxide dismutase transgenic brain accumulates hydrogen peroxide after perinatal hypoxia ischemia. Ann Neurol 44:357364.

221. Bursch W (2001) The autophagosomal-lysosomal compartment in programmed cell death. Cell Death Differ 8:569-581

222. Xue L, Fletcher GC, Tolkovsky AM (1999) Autophagy is activated by apoptotic signalling in sympathetic neurons: an alternative mechanism of death execution. Mol Cell Neurosci 14:180198

223. Hara T, Nakamura K, Matsui M et al (2006) Suppression of basal autophagy in neural cells causes neurodegenerative disease in mice. Nature 441:885-889

224. Komatsu M, Waguri S, Chiba T et al (2006) Loss of autophagy in the central nervous system causes neurodegeneration in mice. Nature 441:880-884

225. Kabeya Y, Mizushima N, Ueno T et al (2000) LC3, a mammalian homologue of yeast Apg8p, is localized in autophagosome membranes after processing. Embo J 19:5720-5728

226. Kabeya Y, Mizushima N, Yamamoto A et al (2004) LC3, GABARAP and GATE16 localize to autophagosomal membrane depending on form-II formation. J Cell Sci 117:2805-2812

227. Asanuma K, Tanida I, Shirato I et al (2003) MAP-LC3, a promising autophagosomal marker, is processed during the differentiation and recovery of podocytes from PAN nephrosis. Faseb J 17:1165-1167

228. Yu WH, Kumar A, Peterhoff C et al (2004) Autophagic vacuoles are enriched in amyloid precursor protein-secretase activities: implications for beta-amyloid peptide over-production and localization in Alzheimer's disease. Int J Biochem Cell Biol 36:25312540

229. Kuan CY, Yang DD, Samanta Roy DR et al (1999) The Jnk1 and Jnk2 protein kinases are required for regional specific apoptosis during early brain development. Neuron 22:667-676

230. Marin-Teva JL, Dusart I, Colin C et al (2004) Microglia promote the death of developing Purkinje cells. Neuron 41:535-547 